\title{
Diamondoids and Thiadiamondoids Generated From Hydrothermal Pyrolysis of Crude Oil and TSR Experiments
}

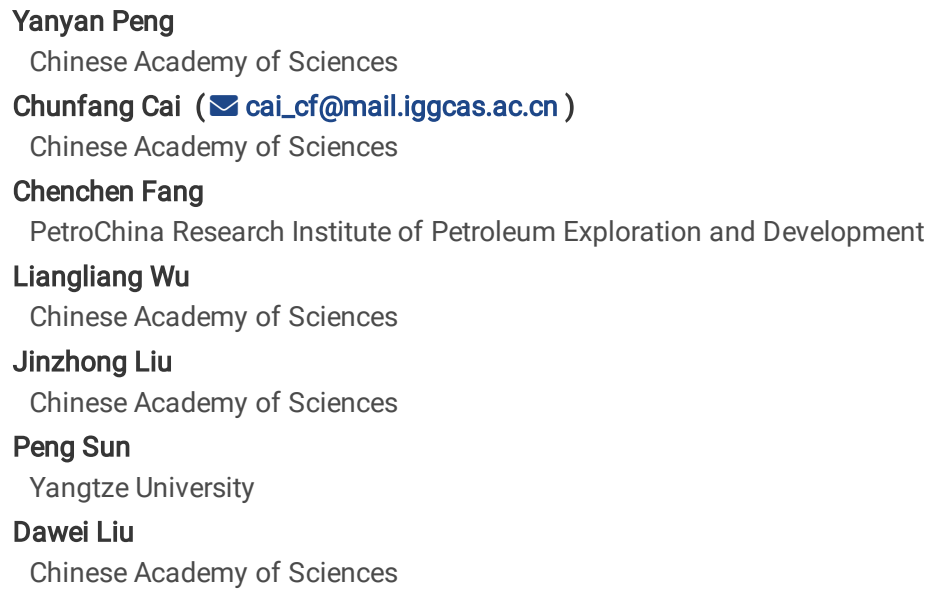




\section{Abstract}

Diamondoid compounds are widely used to reflect thermal maturation of high mature source rocks or oils and oil cracking extents. However, diamondoids and thiadiamondoids were demonstrated to have newly been generated and decomposed in our hydrothermal pyrolysis of crude oil and TSR experiments. Our results show that adamantanes and diamantanes are generated primarily within the maturity range $0.48-2.1 \%$ and $1.2-3.0 \%$ EasyRo, respectively. Their formation is enhanced and the decomposition of diamantanes obviously lags behind at elevated temperatures compared with anhydrous experiments. MDI, EAI, DMAI-1, DMDI-2 may serve as reliable maturity proxies at > ca.1.0\% EasyRo, and other isomerization indices (TMAI-1, TMAI-2 and DMAI-2) are effective for the highly mature organic matter at EasyRo $>2.0 \%$. The extent of oil cracking (EOC) calculated from the broadly used 3-+4-MD method (Dahl et al., 1999) is proven to overestimate, especially for highly cracked samples due to the new generation of 3-4-MD. Still, it can be corrected using a new formula at $<3.0 \%$ EasyRo. Other diamondoid-related indices (e.g. EAI, DMDI-2, As/Ds, MAs/MDs, DMAs/DMDs, and DMAs/MDs) can also be used to estimate EOC. However, these indices cannot be applied to TSR-altered petroleum. TSR is experimentally confirmed to generate diamantanes and thiaadmantanes at $1.81 \%$ EasyRo via direct reactions of reduced S species with hydrocarbons and accelerate the decomposition of diamantanes at $>3.0 \%$ EasyRo compared with thermal chemical alteration (TCA).

\section{Introduction}

Nanometer-sized polycyclic diamondoid hydrocarbons (also polymantanes) appear in petroleum (crude oil and condensates), coal and sedimentary rock in the geosphere ${ }^{1-8}$, and are considered to form during early diagenesis ${ }^{7,9,10}$. Results of numerous laboratory syntheses suggest that diamondoids can generate in mudstone and shale source rocks by carbonium ion rearrangements of specific strained polycyclic alkane precursors under thermal stress in the presence of strong Lewis acids acting as catalysts ${ }^{4,11,12}$. Diamondoids have high thermal stability because they possess a unique ring system composed of cages with three or more fused chair cyclohexane rings. They are considered stable when other hydrocarbons are being cracked down. Therefore, diamondoids can provide new insights into thermal maturation at high mature source rocks or oils using their isomerization proxies, and 3-+4-methyl diamondoid (3-+4-MD) concentrations can be used to reflect oil cracking extents ${ }^{5}$.

However, diamondoids have been formed by the pyrolysis of crude oils ${ }^{13}$ and all four oil fractions ${ }^{14-16}$, as well as compounds, such as $C_{16}, C_{19}, C_{22}, C_{34}$ and $\mathrm{C}_{36}$ n-alkanes ${ }^{17}$ and $\beta$-ionone ${ }^{18}$ without catalysis. All these pyrolysis experiments were conducted in dry conditions, ignoring the effect of water on oil cracking. It is typically recognized that as a ubiquitous substance in sedimentary basins, water can react with organic compounds to provide hydrogen atoms and may have been involved in quite many reactions ${ }^{19-22}$, hydrothermal pyrolysis of organic matter at elevated temperatures have been shown to generate gases more similar to natural gases ${ }^{23,24}$. On the other hand, diamondoid has been proposed to create by thermochemical sulfate reduction ${ }^{25}$ (TSR), a process whereby aqueous sulfate and petroleum compounds react at high temperatures $\left(\varangle>120^{\circ} \mathrm{C}\right)$ to result in elevated $\mathrm{H}_{2} \mathrm{~S}$ concentrations in many carbonate reservoirs ${ }^{26-29}$. This is based on the evidence that TSR-altered oils and condensates in the Cambrian and Ordovician in the Tarim basin and Smackover Formation in the US Gulf Coast have much higher concentrations of diamondoids than non- or minor TSR-altered oils which experienced higher heating.

The diamondoid isomerization ratios are used to assess the thermal maturity of crude oils and source rocks ${ }^{30-32}$ based on the more stable thermodynamic properties of bridge carbon substitution in isomers $4,10,33$. There are nine isomerization indices: MAI [1-MA/(1-MA + 2-MA)]; EAI [1-EA/(1-EA + 2-EA)]; DMAl-1 [1,3DMA/(TMA + 1,3,4-TMA)]; TMAI-2 [1,3,5-TMAI/(1,3,5-TMA + 1,3,6-TMA)]; MDI [4-MD/(4-MD + 1-MD + 3-MD)]; DMDI-1 [4,9-DMD/(4,9-DMD + 3,4-DMD)]; and DMDI-2 [4,9-DMD/(4,9-DMD +4,8-DMD)] $]^{9,10,13,16,30,32,34}$. However, the maturity scopes for the application of each index are still controversial. Also, the isomerization of diamondoids is proposed to enhance due to TSR. As a result, diamondoid-based proxies cannot be used to reflect maturity and lithology in the TSR active areas ${ }^{25}$. However, these proposals have not been confirmed from simulation experiments and the mechanisms for the generation of diamondoids from TSR remain confused.

In the present study, hydrothermal pyrolysis and TSR experiments were carried out under the same experimental conditions as those of anhydrous pyrolysis of Fang et al. (2012) $)^{13}$. The objectives of this study are to: (1) clarify the effect of water on yields of diamondoids; (2) ascertain whether TSR will lead to the new generation of diamondoids and thiadiamondoids; (3) calibrate the reliable EasyRo maturity range of isomerization-related diamondoid proxies; (4) develop diamondoid-related indices to reflect oil cracking extents (EOCs). Thus, the study will have a broad application in petroleum evaluation and thus exploration.

\section{Experimental Methods And Samples}

\subsection{Sample preparation}

A typical black oil was collected from the HD23 well of the Tarim Basin, NW China, used by Fang et al. $(2012 \& 2013)^{13,16}$. The oil contains well-preserved, mono-modal distribution of $n$-alkanes, and abundant biomarkers and has not undergone obvious biodegradation and thermal degradation. This oil is in the early stage of the oil generation window (0.6-0.8\%) as indicated by some maturity parameters, such as the methylphenanthrene index (MPI). More details can be found in Fang et al. (2013) ${ }^{16}$. Quantitative analysis showed that this oil contained relatively low concentrations of adamantanes and diamantanes (359 $\mu \mathrm{g} / \mathrm{g}$ for adamantanes and $79.8 \mu \mathrm{g} / \mathrm{g}$ for diamantanes). To eliminate the effect of these diamondoids on the quantification of the diamondoid generated during oil cracking, the oil sample was evaporated in a fume hood for $120 \mathrm{~h}$ before the pyrolysis experiment to remove the original adamantanes according to the method described by Fang et al. (2012) ${ }^{13}$. The gas chromatography-triple quadrupole mass spectrometry (GC-MS-MS) showed that no adamantanes have remained in the evaporated oil.

Another oil sample (ZS1-L oil) was obtained from the ZS1 well in the Tazhong of the Tarim basin. This oil has a low sulfur content of $0.18 \%$, API gravity of $48.3^{\circ}$, viscosity of $1.60 \mathrm{mPa} \cdot \mathrm{s}$, density of $0.789 \mathrm{~g} / \mathrm{cm}^{3}$ at $20^{\circ} \mathrm{C}$ and is composed of saturates (84.2\%), aromatics (5.5\%), resins (4.6\%) and asphaltene (5.8\%)

Page $2 / 22$ 
with diamantanes of $127 \mu \mathrm{g} / \mathrm{g}$, and $\delta^{34} \mathrm{~S}$ value of $+23.3 \%$.

Inorganic reagents, including $\mathrm{MgSO}_{4}$ with $\delta^{34} \mathrm{~S}$ of $+3.75 \%$, elemental $\mathrm{S}$ with $\delta^{34} \mathrm{~S}$ of $-6.3 \%$ o, $\mathrm{CaSO}_{4} \cdot 2 \mathrm{H}_{2} \mathrm{O}$ with $\delta^{34} \mathrm{~S}$ of $+21.3 \%$, sodium chloride $(\mathrm{NaCl})$ and magnesium chloride $\left(\mathrm{MgCl}_{2}\right)$, were purchased from Sigma-Aldrich (St. Louis, $\mathrm{MO}$ ) and are analytical grade (>99.9\% purity).

\subsection{Confined pyrolysis experiments}

Pyrolysis experiments were conducted using two methods, gold tubes and quartz tubes, depending on the volumes of tubes. For TSR experiments, the liquid chromatographic (LC) separation of thiadiamondoids needs to recover sufficient pyrolysates (pyrolysis products). Hence, gold tubes were used for hydrothermal experiments and quartz tubes were used for TSR experiments. The thermal maturation of samples was calculated using the Easy\%Ro approach developed by Sweeney and Burnham (1990) ${ }^{35}$. The pyrolysates were collected and then analyzed using GC-MS and GC-MS-MS

\subsubsection{Quartz tube pyrolysis experiments}

$110 \mathrm{~mm}$-long quartz tubes with $20 \mathrm{~mm}$ internal diameter, $1 \mathrm{~mm}$ thick wall, giving a total reactor volume of approximately $25 \mathrm{~mL}$, were used for the TSR Experiments. Before loading the tubes, each tube was cleaned using distilled milli-Q water and heated to $450{ }^{\circ} \mathrm{C}$. The solid or liquid reactants were accurately loaded or injected into tubes by a small funnel with an outside diameter slightly smaller than the inner diameter of the quartz tubes. After that, the other end of the tubes was sealed under vacuum conditions. Finally, the tubes with samples loaded were put into autoclaves and desired temperature programs were carried out. After the desired temperature or time was reached, each autoclave was quenched to room temperature before being opened.

We used the $\mathrm{Mg}^{2+}$-talc-silica system as a mineral buffer at elevated temperatures to keep the in-situ pH in a narrow range (pH $\left.\sim 3\right)^{36}$. Thus, each quartz tube was loaded with $30 \mathrm{mg}$ talc, $30 \mathrm{mg}$ silica, $100 \mathrm{~mL}$ distilled milli-Q water solution with $5.6 \mathrm{wt} . \% \mathrm{MgCl}_{2}, 10 \mathrm{wt} . \% \mathrm{NaCl}$ and 0.56 wt.\% $\mathrm{MgSO}_{4}$ or $0.8 \mathrm{wt} . \%$ $\mathrm{CaSO}_{4} \cdot 2 \mathrm{H}_{2} \mathrm{O}$. The approach used to regulate in situ chemical conditions for our study relies on chemical reactions known to proceed rapidly at the temperature and pressure conditions of the experiments ${ }^{37,38}$. More details related to the mineral buffer approach are given by Zhang et al. $(2008,2012)^{36,39}$.

To effectively simulate TSR experiments, two groups of experiments were conducted. Although anhydrite appears to be the reactive oxidant and is replaced by calcite and dolomite in natural TSR reservoirs ${ }^{26-28,40-44}$, it is generally not used in laboratory TSR studies due to its low solubility ${ }^{17,45-47}$. Magnesium (Mg ${ }^{2+}$ ) is always present in natural TSR reservoirs and may play a catalytic role in natural TSR processes. Therefore, two sulfates with large different sulfur isotope values ( $\mathrm{MgSO}_{4}: 3.74 \%$; $\mathrm{CaSO}_{4} \cdot 2 \mathrm{H}_{2} \mathrm{O}: 21.3 \%$ ) were used in the present study for the comparison of the $\delta^{34} \mathrm{~S}$ values of $\mathrm{H}_{2} \mathrm{~S}$. Group1: $100 \mathrm{mg}$ of $\mathrm{ZS} 1-\mathrm{L}$ oil sample, $25 \mathrm{mg}$ elemental S, $100 \mathrm{mg} \mathrm{MgSO}{ }_{4}$ and $100 \mathrm{~mL}$ solution ( $\mathrm{Mg}^{2+}$-talc-silica system); Group2: $100 \mathrm{mg}$ of ZS1-L oil sample, 25 mg elemental S, $100 \mathrm{mg}$ $\mathrm{CaSO}_{4} \cdot 2 \mathrm{H}_{2} \mathrm{O}$ and $100 \mathrm{~mL}$ solution ( $\mathrm{Mg}^{2+}$-talc-silica system). Blank experiments with $100 \mathrm{mg}$ of $\mathrm{ZS} 1-\mathrm{L}$ oil sample and $100 \mathrm{~mL}$ solution (5.6 wt.\% MgCl 2,10 wt. $\% \mathrm{NaCl})$ were performed in parallel. Group 1 experiments heated from $336^{\circ} \mathrm{C}$ to $600^{\circ} \mathrm{C}$ at constant heating rates $\left(20^{\circ} \mathrm{C} / \mathrm{h}\right)$. In $\mathrm{Group} 2 \mathrm{experiments,} \mathrm{the}$ pyrolysis temperature and time were $360^{\circ} \mathrm{C}$ and $48-840 \mathrm{~h}$. The error of the recorded temperatures is $< \pm 1^{\circ} \mathrm{C}$.

\subsubsection{Gold tube pyrolysis experiments}

Oil pyrolysis in hydrothermal conditions was conducted in sealed gold tubes with an internal diameter of $5 \mathrm{~mm}$ and wall thickness of $0.5 \mathrm{~mm}$ after the method of Fang et al. (2012) ${ }^{13}$. Each tube was between 40 and $50 \mathrm{~mm}$ long, giving a total reactor volume of approximately $0.5 \mathrm{~mL}$. One end of each tube was crimped and sealed using an argon arc welder. Before loading the samples, the open-ended tubes were heated to $600{ }^{\circ} \mathrm{C}$ to remove any residual organic material. Then, specific amounts of samples (i.e. oil and water with the weight ratio of 1:1) were loaded into the gold tubes, which were subsequently flushed with argon for 5 min and sealed under an argon atmosphere. Individual sealed gold tubes were later placed in separate stainless-steel autoclaves and inserted into a pyrolysis oven. The ovens were heated from $336^{\circ} \mathrm{C}$ to $600{ }^{\circ} \mathrm{C}$ at two constant rates of $20^{\circ} \mathrm{C} / \mathrm{h}$ and $2^{\circ} \mathrm{C} / \mathrm{h}$, respectively, under the constant pressure of $50 \mathrm{MPa}$. After reaching desired reaction temperature and the pressure was released, the tubes were taken out from autoclaves.

Two parallel gold tubes were positioned in each autoclave to quantify diamondoid hydrocarbons and the extent of oil cracking (EOC) in pyrolysates. To remove any potential organic contaminants from the exterior of the gold tubes, they were cleaned in dichloromethane and allowed to air dry. Following this cleaning procedure, the tubes were cooled for 25-30 min using liquid nitrogen. Upon removing the liquid nitrogen, the first cleaned gold tube for diamondoid analysis was rapidly cut in half and placed in a $4 \mathrm{ml}$ sample vial filled with isooctane to minimize loss of volatile components. The parallel gold tube for EOC analysis was first cut off welded ends and then rapidly cut into four equal pieces. The four tube pieces were quickly placed into a $10 \mathrm{ml}$ sample vial filled with dichloromethane and allowed to soak overnight (12-20 h). The vials containing the gold tube pieces were then sonicated repeatedly to recover the pyrolysates. The vials were then opened for a minimal amount of time to remove the pieces of gold tubing and their transfer to $4 \mathrm{~mL}$ sample vial containing dichloromethane. Asphaltenes were then precipitated from the products by adding 50 -fold (volume ratio for $\mathrm{n}$-hexane/bitumen) cold $\mathrm{n}$-hexane and removed by centrifugation. Then the absolute amount of liquid hydrocarbon was weighed on behalf of residual liquid hydrocarbons.

\subsection{Quantification of diamondoids (GC-MS-MS) and thiaadamantanes (GC-MS)}

About $50 \mu \mathrm{L}$ standards isooctane with $n$-dodecane- $d_{26}$ and $n$-hexadecane- $d_{34}$ were injected into the sample vial. The vial was ultrasonically treated for 10 min to improve the dissolution of pyrolysates. Leaving the vial for 12 hours to precipitate asphaltenes, a volume of the supernatant was transferred into a $2 \mathrm{ml}$ auto-sampler vial for GC-MS-MS. The identification and measurement of diamondoids using the GC-MS-MS method was described in detail elsewhere ${ }^{48}$

The liquid chromatographic (LC) separation of thiadiamondoids was done according to the method of Wei et al. (2012) ${ }^{49}$ : LC on silver nitrate-impregnated silica gel was used to fractionate samples into saturate, aromatic, and sulfidic fractions by sequential elution using hexane, dichloromethane, and acetone, respectively. Care was taken to avoid drying the sulfidic fractions during evaporation and concentration to smaller volumes down to $50-150 \mu l$ and analyzed for thiaadamantanes using GC-MS method as detailed in Cai et al. (2016b) ${ }^{25}$

Page $3 / 22$ 


\subsection{Sulfur isotope analysis}

For $\delta^{34} \mathrm{~S}$ of the $\mathrm{H}_{2} \mathrm{~S}$ (converted to $\mathrm{Ag}_{2} \mathrm{~S}$ ) was conducted at the Institute of Geology and Geophysics, Chinese Academy of Sciences. The dried $\mathrm{Ag}_{2} \mathrm{~S}$ and $\mathrm{Cu}_{2} \mathrm{O}$ were generally mixed in a proportion of $1: 10$ and then combusted at $1100^{\circ} \mathrm{C}$ under vacuum to produce $\mathrm{SO}_{2}$. The resulting $\mathrm{SO}_{2}$ was sealed within pyrex tubing and analyzed on a Thermo Delta S mass spectrometer. Sulfur isotope values are expressed as per mil (\%o) deviations from the sulfur isotope composition of the Vienna Canyon Diablo Troilite (VCDT) using the conventional delta $\left(\delta^{34} S\right)$ notation. Isotopic results were generally reproducible within $\pm 0.3 \%$.

\section{Results}

The yield of the individual diamondoid compounds is used to characterize the variation in the absolute amount of diamondoids during the experiments and expresses as the mass of diamondoids generated at each temperature point relative to the initial weight of the oil in each gold tube or quartz tube, according to

$Y_{i}=M_{i} / M_{0}(1)$

where $Y_{i}$ is the yield of the particular diamondoids (e.g., an individual diamondoid compound, a group of compounds, or the total diamondoids); $M_{i}$ is the mass $(\mu \mathrm{g})$ of the relevant diamondoids; $M_{0}$ is the initial mass $(\mathrm{g})$ of the diamondoid-generating substance (original oil mass loaded in the tube)

In this study, 32 diamondoid compounds, including 22 adamantanes and 10 diamantanes were identified by GC-MS-MS, and their concentrations were quantified as in Table 1. Meanwhile, several homologous series of alkylated 2-thiaadamantanes were identified by GC-MS, the tentative peak assignments of alkylated 2-thiaadamantanes were given in Fig. 1. 
Table 1

The detected diamondoid compounds in this study.

\begin{tabular}{|c|c|c|c|}
\hline Peak number & Diamondoid Compound & $\mathrm{m} / \mathrm{z}$ & Abbreviation \\
\hline 1 & Adamantane & $136 \rightarrow 93$ & A \\
\hline 2 & 1-Methyladamantane & $150 \rightarrow 135$ & 1-MA \\
\hline 3 & 2-Methyladamantane & $150 \rightarrow 135$ & 2-MA \\
\hline 4 & 1-Ethyladamantane & $164 \rightarrow 135$ & 1-EA \\
\hline 5 & 2-Ethyladamantane & $164 \rightarrow 135$ & 2-EA \\
\hline 6 & 1,3-Dimethyladamantane & $164 \rightarrow 149$ & 1,3-DMA \\
\hline 7 & 1,4-Dimethyladamantane (cis) & $164 \rightarrow 149$ & 1,4-DMA (cis) \\
\hline 8 & 1,4-Dimethyladamantane (trans) & $164 \rightarrow 149$ & 1,4-DMA (trans) \\
\hline 9 & 1,2-Dimethyladamantane & $164 \rightarrow 149$ & 1,2-DMA \\
\hline 10 & 2,6- + 2,4-Dimethyladamantane & $164 \rightarrow 149$ & $2,6-+2,4-D M A$ \\
\hline 11 & 1-Ethyl,3-methyladamantane & $178 \rightarrow 149$ & 1-E,3-MA \\
\hline 12 & 1,3,5-Trimethyladamantane & $178 \rightarrow 163$ & $1,3,5-\mathrm{TMA}$ \\
\hline 13 & 1,3,6-Trimethyladamantane & $178 \rightarrow 163$ & 1,3,6-TMA \\
\hline 14 & 1,3,4-Trimethyladamantane (cis) & $178 \rightarrow 163$ & 1,3,4-TMA (cis) \\
\hline 15 & 1,3,4-Trimethyladamantane (trans) & $178 \rightarrow 163$ & 1,3,4-TMA (trans) \\
\hline 16 & 1,2,3-Trimethyladamantane & $178 \rightarrow 163$ & 1,2,3-TMA \\
\hline 17 & 1-Ethyl,3,5-dimethyladamantane & $192 \rightarrow 163$ & 1-E,3,5-DMA \\
\hline 18 & 1,3,5,7-Tetramethyladamantane & $192 \rightarrow 177$ & 1,3,5,7-TeMA \\
\hline 19 & 1,2,5,7-Tetramethyladamantane & $192 \rightarrow 177$ & 1,2,5,7-TeMA \\
\hline 20 & 1,3,5,6-Tetramethyladamantane & $192 \rightarrow 177$ & 1,3,5,6-ТeMA \\
\hline 21 & 1,2,3,5-Tetramethyladamantane & $192 \rightarrow 177$ & 1,2,3,5-ТeMA \\
\hline 22 & 1-Ethyl-3,5,7-trimethyladamantane & $192 \rightarrow 177$ & 1-E-3,5,7-TMA \\
\hline I.S.-1 & n-Dodecane-d26 & $196 \rightarrow 82$ & $\mathrm{n}-\mathrm{C} 12-\mathrm{d} 26$ \\
\hline 23 & Diamantane & $188 \rightarrow 131$ & $\mathrm{D}$ \\
\hline 24 & 4-Methyldiamantane & $202 \rightarrow 187$ & 4-MD \\
\hline 25 & 1-Methyldiamantane & $202 \rightarrow 187$ & 1-MD \\
\hline 26 & 3-Methyldiamantane & $202 \rightarrow 187$ & 3-MD \\
\hline 27 & 4,9-Dimethyldiamantane & $216 \rightarrow 201$ & 4,9-DMD \\
\hline \multirow[t]{2}{*}{28} & 1,4-Dimethyldiamantanet & $216 \rightarrow 201$ & 1,4-DMD + 2,4-DMD \\
\hline & 2,4-Diamethyldiamantane & & \\
\hline 29 & 4,8-Dimethyldiamantane & $216 \rightarrow 201$ & 4,8-DMD \\
\hline 30 & 3,4-Dimethyldiamantane & $216 \rightarrow 201$ & 3,4-DMD \\
\hline 31 & 1,4,9-Trimethyldiamantane & $230 \rightarrow 215$ & 1,4,9-TMD \\
\hline 32 & 3,4,9-Trimethyldiamantane & $230 \rightarrow 215$ & 3,4,9-TMD \\
\hline I.S.-2 & n-Hexadecane-d34 & $260 \rightarrow 82$ & $n-C 16-d 34$ \\
\hline
\end{tabular}

\subsection{Hydrothermal experiments of HD23 oil}

The first sample was obtained at EasyRo $=0.48 \%$ during hydrothermal pyrolysis of an HD23 oil with yields of adamantanes and diamantanes of $137.4 \mu \mathrm{g} / \mathrm{g}$ and $72.4 \mu \mathrm{g} / \mathrm{g}$, respectively (Supplementary Table S1 and Fig. 2). The yields of adamantanes continue to increase until EasyRo $2.1 \%$, and at > EasyRo $2.1 \%$, adamantanes show a decrease. The yields of diamantanes are rising from EasyRo 0.48\% until EasyRo 3.0\% (Fig. 2). Adamantanes dominate the generated diamondoids (Fig. 2): adamantanes have concentrations of $137.4-563.9 \mu \mathrm{g} / \mathrm{g}$, which are three times more than diamantanes (from $72.4-182.1 \mu \mathrm{g} / \mathrm{g}$ ) with the maximum value of $563.9 \mu \mathrm{g} / \mathrm{g}$ and $182.1 \mu \mathrm{g} / \mathrm{g}$ at $2.1 \%$ EasyRo and $3.0 \%$ EasyRo, respectively. 
As for individual compounds, the amounts of generated Adamantane (A), Methyladamantane (MA), Ethyladamantane (EA), Dimethyladamantane (DMA) and Trimethyladamantane (TMA) are shown to increase with EasyRo in the range of $0.48-2.1 \%$ and rapid decrease in the EasyRo range $2.1-2.5 \%$. The yields of Tetramethyladamantane (TeMA) increase in the EasyRo range $0.48-2.5 \%$ and a reversal occurs above the 2.5\% EasyRo (Fig. 3 and Supplementary Table S1). Similarly, the yields of different types of diamantanes keep nearly constant in the oil samples from experiments at EasyRo $<1.5 \%$ (Fig. $3 c$, $f \& i)$. Subsequently, the yields of Methyldiamantane (MD), Dimethyldiamantane (DMD) and Trimethyldiamantane (TMD) increase in the EasyRo range 1.5-3.0\% and a reversal occur above the 3.0\% EasyRo (Fig. 3). In addition, adamantanes generated during oil cracking are dominated by DMA, followed by TMA, MA, TMA, EA and A, while diamantanes are dominated by MD, DMD, TMD and Diamantane (D).

\subsection{TSR experiments with ZS1-L oil}

To investigate the effect of TSR on the generation of diamondoids, two groups of experiments with $\mathrm{MgSO}_{4}(\mathrm{Group})$ and $\mathrm{CaSO} \mathrm{S}_{4} \cdot 2 \mathrm{H}_{2} \mathrm{O}\left(\mathrm{Group}_{2}\right)$ were conducted, respectively. The yields of hydrogen sulfide $\left(\mathrm{H}_{2} \mathrm{~S}\right)$ generated in hydrothermal experiments with $\mathrm{MgSO}_{4}$ apparently are higher than those with $\mathrm{CaSO}_{4} \cdot 2 \mathrm{H}_{2} \mathrm{O}$ (Table 2). Group 1 : The $\mathrm{H}_{2} \mathrm{~S}$ yields increases substantially at EasyRo $=0.57-2.5 \%$ from $9.57 \mathrm{mmol} / \mathrm{g}$ to $17.43 \mathrm{mmol} / \mathrm{g}$, and then decreases slightly at EasyRo $=2.5-3.87 \%$ from $17.43 \mathrm{mmol} / \mathrm{g}$ to $14.62 \mathrm{mmol} / \mathrm{g}$ (Table 2). Group 2: $\mathrm{The}_{2} \mathrm{~S}$ yields are substantially at EasyRo $=1.13-1.69 \%$ from 8.92 $\mathrm{mmol} / \mathrm{g}$ to $11.47 \mathrm{mmol} / \mathrm{g}$ (Table 2). Moreover, the evolution trends for $\delta^{34} \mathrm{~S}_{\mathrm{H} 2 \mathrm{~S}}$ in two groups of experiments are totally different (Table 2 and Fig. 4 ). There is a positive correlation between $\delta^{34} \mathrm{~S}$ values of $\mathrm{H}_{2} \mathrm{~S}$ and EasyRo in Group1 (Table 2), and the $\delta^{34} \mathrm{~S}$ values of $\mathrm{H}_{2} \mathrm{~S}$ are from $-5.00 \%$ o to $-2.45 \%$ with EasyRo from $0.57-3.87 \%$ (Table 2). In contrast, $\delta^{34} \mathrm{~S}_{\mathrm{H} 2 \mathrm{~S}}$ in Group 2 is close to that of elemental S (Table 2 and Fig. 4). The $\delta^{34} \mathrm{~S}$ of $\mathrm{H}_{2} \mathrm{~S}$ generated in Group 2 ranged from $5.79 \%$ o to $-6.79 \%$, within $\pm 1 \%$ o of elemental S $(-6.3 \%$ o).

Table 2

Gas yields (mmol/g oil) and ${ }^{34} \mathrm{~S}$ isotopic ratios of $\mathrm{H}_{2} \mathrm{~S}$ in hydrothermal experiments involving $\mathrm{S}^{0}, \mathrm{MgSO}_{4}$ and $\mathrm{CaSO}_{4} \cdot 2 \mathrm{H}_{2} \mathrm{O}$.

\begin{tabular}{|c|c|c|c|c|c|c|c|c|}
\hline Temperature & Time & EasyRo & $\mathrm{MgSO}_{4} / \mathrm{CaSO}_{4} \cdot 2 \mathrm{H}_{2} \mathrm{O}$ & so & $\mathrm{H}_{2} \mathrm{~S}$ & $\mathrm{CO}_{2}$ & $\mathrm{H}_{2} \mathrm{~S} / \mathrm{S}^{0}$ & $\delta^{34} S_{H 2 S}$ \\
\hline$\left({ }^{\circ} \mathrm{C}\right)$ & (h) & (\%) & (mmol/g oil) & & & & & (\%o) \\
\hline \multicolumn{9}{|c|}{ Group1\#: Non-isothermal pyrolysis of ZS1-L oil involving $\mathrm{S}^{0}$ and $\mathrm{MgSO}_{4}$ under constant rate of $20^{\circ} \mathrm{C} / \mathrm{h}$} \\
\hline 336 & & 0.57 & 13.93 & 13.68 & 9.66 & 0.38 & 0.71 & -5.00 \\
\hline 360 & & 0.68 & 13.45 & 12.85 & 9.42 & 0.47 & 0.73 & -4.87 \\
\hline 384 & & 0.79 & 13.47 & 12.85 & 9.49 & 0.44 & 0.74 & -4.93 \\
\hline 408 & & 0.96 & 13.52 & 12.47 & 10.57 & 0.54 & 0.85 & -3.96 \\
\hline 432 & & 1.19 & 13.45 & 12.91 & 11.04 & 0.63 & 0.86 & -3.68 \\
\hline $456^{*}$ & & 1.47 & - & - & - & 0.51 & - & - \\
\hline 456 & & 1.47 & 13.64 & 12.24 & 11.36 & 0.84 & 0.93 & \\
\hline 480 & & 1.81 & 13.05 & 12.92 & 12.28 & 1.07 & 0.95 & -3.05 \\
\hline 504 & & 2.19 & 11.41 & 11.59 & 15.12 & 1.15 & 1.31 & -2.74 \\
\hline 528 & & 2.62 & 12.86 & 12.79 & 17.43 & 1.70 & 1.36 & - \\
\hline 552 & & 3.06 & 13.84 & 13.00 & 16.96 & 1.93 & 1.30 & -2.97 \\
\hline 576 & & 3.5 & 13.35 & 12.18 & 15.58 & 1.99 & 1.28 & -2.49 \\
\hline 600 & & 3.87 & 13.41 & 13.11 & 14.62 & 2.14 & 1.12 & -2.45 \\
\hline \multicolumn{9}{|c|}{ Group2\#: Isothermal pyrolysis of ZS1-L oil involving $\mathrm{S}^{0}$ and $\mathrm{CaSO}_{4} \cdot 2 \mathrm{H}_{2} \mathrm{O}$ at $360^{\circ} \mathrm{C}$ for $48-840 \mathrm{~h}$} \\
\hline $360 *$ & 432 & 1.54 & - & - & - & 1.23 & - & - \\
\hline 360 & 48 & 1.13 & 13.55 & 13.09 & 11.46 & 1.71 & 0.88 & - \\
\hline 360 & 96 & 1.25 & 13.79 & 12.38 & 10.53 & 1.75 & 0.93 & - \\
\hline 360 & 144 & 1.32 & 13.70 & 13.45 & 11.47 & 1.75 & 0.85 & -5.97 \\
\hline 360 & 192 & 1.38 & 13.33 & 12.39 & 8.92 & 1.74 & 0.78 & -6.20 \\
\hline 360 & 288 & 1.46 & 13.75 & 13.74 & 9.48 & 1.99 & 0.69 & -5.78 \\
\hline 360 & 432 & 1.54 & 13.79 & 13.36 & 10.26 & 2.21 & 0.71 & -6.28 \\
\hline 360 & 648 & 1.63 & 13.70 & 13.25 & 9.25 & 2.21 & 0.65 & -6.79 \\
\hline 360 & 840 & 1.69 & 13.63 & 14.18 & 11.14 & 2.49 & 0.73 & -6.79 \\
\hline
\end{tabular}

Page 6/22 
As for the yields of diamondoids, only Group 1 are discussed in this study with the occurrence of TSR. See 4.1 for details. And only results of diamantanes are listed in the following since evaporative losses of adamantanes during sample work up (Table 3). Our results show that the yields of total diamantanes and 3+4-MD progressively rises from $127 \mu \mathrm{g} / \mathrm{g}$ and $45 \mu \mathrm{g} / \mathrm{g}$ before the heating to a maximum of $240 \mu \mathrm{g} / \mathrm{g}$ and $80 \mu \mathrm{g} / \mathrm{g}$ at EasyRo $1.81 \%$, respectively (Fig. $5 \mathrm{a} \& \mathrm{c}$ ). At EasyRo $>1.81 \%$, both 3-+4-MD and diamantanes show a decrease. Similar to the hydrothermal experiments, diamantanes generated during TSR are dominated by MD, followed by DMD, TMD and D (Fig. 5b). Interestingly, thiadiamondoids including thiaadmantane and methyl thiaadmantanes isomers were detected from the oil after TSR pyrolysis in the $480{ }^{\circ} \mathrm{C}$ experiments (1.81\% EasyRo) with the maximum yield of diamantanes (Fig. 1).

Table 3

The yields ( $\mu \mathrm{g} / \mathrm{g}$ oil) of individual diamantane compounds are identified in Table 1 at each heating temperature of the TSR experiments.

\begin{tabular}{|c|c|c|c|c|c|c|c|c|c|c|c|c|c|c|c|c|}
\hline EasyRo & $\begin{array}{l}\mathrm{T} \\
\left(20^{\circ} \mathrm{C} / \mathrm{h}\right)\end{array}$ & D & 4-MD & 1-MD & 3-MD & $\begin{array}{l}4,9- \\
\text { DMD }\end{array}$ & $\begin{array}{l}1,4- \\
+2,4- \\
\text { DMD }\end{array}$ & $\begin{array}{l}4,8- \\
\text { DMD }\end{array}$ & $\begin{array}{l}\text { 3,4- } \\
\text { DMD }\end{array}$ & $\begin{array}{l}\text { 1,4,9- } \\
\text { TMD }\end{array}$ & $\begin{array}{l}\text { 3,4,9- } \\
\text { TMD }\end{array}$ & MD & DMD & TMD & $\begin{array}{l}3+4- \\
\text { MD }\end{array}$ & Ds \\
\hline 0 & initial & 14.08 & 20.92 & 13.28 & 23.89 & 5.98 & 6.46 & 8.00 & 14.90 & 3.22 & 10.98 & 58.09 & 35.34 & 14.20 & 44.81 & 121. \\
\hline 0.57 & 336 & 13.86 & 24.30 & 11.42 & 24.81 & 7.09 & 6.36 & 6.66 & 17.43 & 4.35 & 13.28 & 60.53 & 37.55 & 17.63 & 49.11 & $129 . !$ \\
\hline 0.68 & 360 & 15.16 & 24.46 & 13.08 & 25.79 & 7.60 & 6.70 & 7.09 & 16.83 & 4.69 & 13.82 & 63.32 & 38.22 & 18.51 & 50.24 & 135.: \\
\hline 0.79 & 384 & 13.94 & 25.79 & 15.54 & 27.96 & 7.48 & 6.91 & 8.15 & 20.57 & 4.79 & 15.24 & 69.29 & 43.11 & 20.03 & 53.75 & 146.: \\
\hline 0.96 & 408 & 15.66 & 26.31 & 18.26 & 30.31 & 8.97 & 7.68 & 7.66 & 21.82 & 5.34 & 16.87 & 74.87 & 46.13 & 22.21 & 56.61 & $158 . i$ \\
\hline 1.19 & 432 & 11.26 & 17.46 & 15.82 & 44.35 & 8.95 & 10.26 & 10.17 & 26.52 & 7.73 & 24.47 & 77.63 & 55.90 & 32.19 & 61.81 & 176. \\
\hline $1.47^{\star}$ & 456 & 25.42 & 22.60 & 17.32 & 36.07 & 6.13 & 5.56 & 7.76 & 18.50 & 3.70 & 13.01 & 75.99 & 37.95 & 16.71 & 58.67 & 156.1 \\
\hline 1.47 & 456 & 12.27 & 18.57 & 22.03 & 53.08 & 9.13 & 9.50 & 11.49 & 35.28 & 7.77 & 39.84 & 93.67 & 65.40 & 47.61 & 71.64 & $218 .^{\prime}$ \\
\hline 1.81 & 480 & 14.84 & 23.24 & 21.45 & 56.21 & 10.98 & 11.99 & 13.40 & 34.77 & 9.10 & 43.18 & 100.89 & 71.14 & 52.28 & 79.45 & 239. \\
\hline 2.19 & 504 & 9.96 & 18.21 & 16.10 & 40.42 & 8.55 & 8.47 & 9.78 & 32.65 & 6.65 & 31.13 & 74.74 & 59.45 & 37.78 & 58.63 & 181.' \\
\hline 2.62 & 528 & 7.49 & 10.32 & 7.46 & 11.05 & 8.27 & 6.62 & 7.27 & 12.28 & 7.20 & 10.13 & 28.83 & 34.45 & 17.33 & 21.37 & 88.11 \\
\hline 3.06 & 552 & 2.33 & 2.31 & 1.73 & 1.87 & 1.75 & 1.73 & 1.73 & 2.37 & 1.76 & 2.37 & 5.92 & 7.59 & 4.13 & 4.18 & $19.9^{\circ}$ \\
\hline 3.5 & 576 & 0.75 & 0.70 & 0.70 & 0.70 & 0.70 & 0.70 & 0.70 & 0.70 & 0.70 & 0.70 & 2.10 & 2.80 & 1.40 & 1.40 & 7.05 \\
\hline 3.87 & 600 & 1.00 & 0.75 & 0.75 & 0.75 & 0.75 & 0.75 & 0.75 & 0.75 & 0.75 & 0.75 & 2.25 & 3.00 & 1.50 & 1.50 & 7.76 \\
\hline
\end{tabular}

- indicates not detected; * The blank experiment: ZS1-L oil + water heating at $456^{\circ} \mathrm{C}$

\section{Discussion}

\subsection{Formation and decomposition of diamondoids during hydrothermal pyrolysis of an HD23 oil}

Hydrothermal pyrolysis of the HD23 oil shows that both adamantanes and diamantanes were newly generated and decomposed. Still, their yield curves are partially different from the anhydrous ${ }^{13}$ : First, diamondoids were generated in a broader range of EasyRo with higher yields at $<1.7 \%$ EasyRo during the hydrothermal experiments than the anhydrous (Fig. 6), indicating that water promoted the yields of diamondoids at low EasyRo (< 2.0\%). With increasing EasyRo, the differences in the yields of diamondoids between the two became smaller. Among diamondoids, adamantanes show an increase in their yields from $0.48-2.1 \%$ EasyRo (Fig. 6a), and the range is wider than the range of $1.0-2.1 \%$ for the anhydrous experiments. Similarly, diamantanes began to be generated at $0.79 \%$ EasyRo from hydrothermal pyrolysis experiments, much lower than $1.7 \%$ EasyRo for the anhydrous pyrolysis experiments (Fig. $6 \mathrm{~b}$ ). Second, the decomposition of diamantanes and TeMA from the hydrothermal experiments occurred at EasyRo $>3.0 \%$ and EasyRo $>2.5 \%$, obviously lagging behind that from the corresponding anhydrous experiments at EasyRo $>2.5 \%$ and $2.1 \%$, respectively (Fig. $6 \mathrm{~b}$ and Fig. 3). This may indicate that water can delay the decomposition of high molecular weight diamondoids during oil thermal cracking.

Larger yields of diamondoids from hydrothermal pyrolysis than the anhydrous (Fig. 6) can be explained as follow. As the result of ionic reactions, hydrothermal pyrolysis of organic matter generates more considerable amounts of intermediate olefinic and isomeric hydrocarbons than the anhydrous pyrolysis ${ }^{50}$. In turn, the olefins and isomeric hydrocarbons will be hydrogenated by rapid free radical reactions, raising the yields of diamondoids during hydrothermal pyrolysis. That is, combining ionic and free radical reactions can accelerate isomerization and cyclization of these olefinic hydrocarbons to generate the relatively high yields of diamondoids under hydrothermal pyrolysis.

It is necessary to discuss which one, hydrothermal or anhydrous pyrolysis, has the products representing maturation of natural samples, considering the more significant differences in EasyRo for decomposition of diamantanes and yields of diamondoids between the two. The EasyRo for the generation and decomposition of the 3-+4-MD in this study are close to that of natural samples from both coals and rocks, that is, ca. $1.2 \%$ EasyRo vs $1.1 \%$ Ro for the generation and 3.0\% EasyRo vs ca. 4.0\% Ro for the decomposition ${ }^{7}$. In contrast, EasyRo obtained from anhydrous pyrolysis are deviated more from the natural samples, $1.5 \%$ for the generation and $2.5 \%$ for the decomposition ${ }^{13,51,52}$. Ro values are approximately equal to the calculated EasyRo values at EasyRo $<1.5 \sim 2.0 \%$. The differences between Ro and calculated EasyRo are slightly more significant at EasyRo $>1.5 \sim 2.0 \%$, likely due to the change in the chemical composition of solid kerogen with higher maturity levels ${ }^{53}$. This result suggests that hydrothermal pyrolysis has the products closer to the cracking

Page $7 / 22$ 
of natural samples, which is supported by the gas produced from the hydrothermal pyrolysis more similar to the natural gas than anhydrous pyrolysis ${ }^{23}$. Moreover, water is ubiquitous in petroleum reservoirs and may provide $\mathrm{H}$ and $\mathrm{O}$ involved in petroleum generation and evolution ${ }^{38,54}$, suggesting hydrothermal pyrolysis may represent the maturation of natural samples better than the anhydrous.

\subsection{Diamondoids as proxies for thermal maturity}

It is widely accepted those isomerization ratios such as MAI. MDI, EAI, DMAI-1, TMAI-1, TMAI-2, DMDI-1 and DMDI-2 can be used to determine the thermal maturity of highly mature crude oils(Ro $>1.1 \%)^{9,10,30,32,34}$, and they can be applied for different maturity ranges ${ }^{16}$. Isomerization-related diamondoid ratios are unaffected by thermal maturity levels with EasyRo $<2.0 \%$ in anhydrous pyrolysates and used as proxies of thermal maturity at $>2.0 \%$ EasyRo ${ }^{16}$. In this study, MDI, EAI, DMAI-1 and DMDI-2 can be applied to reflect maturity at much lower EasyRo from hydrothermal pyrolysis: $1.47-3.5 \%$ EasyRo for MDI with $\mathrm{R}^{2}$ of 0.8717 (Fig. 7b), $0.86-2.5 \%$ EasyRo for EAl with $R^{2}$ of 0.8412 (Fig. 7c), 1.08-3.5\% EasyRo for DMAl-1 with $\mathrm{R}^{2}$ of 0.8502 (Fig. 7 e) and $1.08-3.5 \%$ EasyRo for DMDI-2 with $\mathrm{R}^{2}$ of 0.9304 (Fig. 7d). This supports that MDI is an effective proxy of maturity at $>1.3 \%$ Ro for either source rock extracts ${ }^{9}$ or hydrothermal pyrolysates ${ }^{10}$. However, consistent with Fang et al. (2012) ${ }^{13}$, MAl in this study seems not related to EasyRo (Fig. 7a), and thus cannot be used as a proxy to assess the thermal maturity of oils. MDI, EAI, DMAI-1, DMDI-2 can serve as reliable maturity indicators with broad EasyRo ranges mainly $>1.0 \%$. In contrast, at EasyRo $<1.0 \%$, diamondoid-related proxies including MDI, EAl, DMAI-1, DMDI-2 show no correlations with EasyRo, suggesting that they cannot be used to determine the maturity of oils and thus source rocks. The previous observation supports this proposal that diamondoid concentrations and distributions are dependent on the source rocks instead of maturity within the oil window 55 .

Other isomerization ratios (e.g., DMAI-2, TMAI-2 and TMAI-1) show good correlations with thermal maturity in the higher EasyRo ranges of 2.08-3.5\% with $\mathrm{R}^{2}$ of $0.9617,0.9752$ and 0.8581 (Fig. $7 \mathrm{~g}-\mathrm{i}$ ). These ratios seem controlled by the parent organic matter during the generation stage of diamondoids (EasyRo < $2.0 \%$ ), and thus may reflect the source feature rather than maturity ${ }^{16}$. They can be used to reflect maturity only at higher maturity levels (>2.0\% EasyRo) as found in Fang et al. (2013) $)^{16}$ and this study. However, unlike other studies, DMDI-1 does not correlate well with EasyRo values in this study (Fig. 7f), probably due to the relatively sizeable analytical error associated with low concentrations of dimethyldiamantanes in the pyrolysates.

\subsection{Diamondoids as proxies for the extent of oil cracking}

Oil cracking involves the thermal breakdown of heavy hydrocarbons to smaller ones, or the process of ultimately converting oil to hydrogen-rich gas and carbon-rich pyrobitumen ${ }^{56}$. In our hydrothermal pyrolysis, we found that the extent of oil cracking (EOC; i.e., the percentage of liquid hydrocarbon converted to gas and pyrobitumen, or $E O C=\left(1-M_{C} M_{0}\right) \times 100, M_{C}$ and $M_{0}$ are residual and initial liquid hydrocarbons, respectively) can rapidly increase to $90 \%$ with the rise in EasyRo from $0.48-1.81 \%$ (Fig. 8a). Oil cracking occurs at slower rates with further increasing maturation as reflected in the increase in EasyRo from $1.81 \%$ $\left(480^{\circ} \mathrm{C}\right)$ to $3.5 \%\left(600^{\circ} \mathrm{C}\right)$ and relatively stable EOC around $90-95 \%$. However, at the high maturity (above $500^{\circ} \mathrm{C}$ ) almost all of the liquid hydrocarbons have been consumed, so the error is around $\pm 5 \%$ from $2.19 \%\left(504^{\circ} \mathrm{C}\right)$ to $3.5 \%\left(600^{\circ} \mathrm{C}\right)$ in the oil pyrolysis experiments.

Oil cracking involves the thermal breakdown of heavy hydrocarbons to smaller ones or ultimately converting oil to hydrogen-rich gas and carbon-rich pyrobitumen. In our hydrothermal pyrolysis, we found that the extent of oil cracking (EOC; i.e., the percentage of liquid hydrocarbon converted to gas and pyrobitumen, or $E O C=\left(1-M_{C} / M_{0}\right) \times 100, \mathrm{M}_{\mathrm{c}}$ and $\mathrm{M}_{\mathrm{O}}$ are residual and initial liquid hydrocarbons, respectively $)$ can rapidly increase to $90 \%$ with rising in EasyRo from $0.48-1.81 \%$ (Fig. 8a). Oil cracking occurs at slower rates with further increasing maturation, as reflected in an increase in EasyRo from $1.81-3.5 \%$ and relatively stable EOC around $90-95 \%$.

EOC can also be calculated as $\left(1-\mathrm{C}_{0} / \mathrm{C}_{\mathrm{c}}\right) \times 100^{5}$, in which 3-+4-MD is assumed not to have newly been generated or decomposed during oil cracking $\left(\mathrm{C}_{0}\right.$ and $\mathrm{C}_{\mathrm{c}}$ are concentrations of 3-+4-MD before and after oil cracking). However, an increase in the 3-+4-MD occurs at ca. 1.2\% EasyRo. The decrease in the 3-+4-MD yield is observed at 3.0\% EasyRo during oil thermal cracking experiments (Fig. 9a), suggesting the assumption does not apply (Fig. 9b). This finding is supported by other pyrolysis experiments ${ }^{8,13,16}$, lending usage of $\left(1-C_{0} / C_{\partial}\right) \times 100 \%$ is suspect. Based on our results, Dahl's formula for EOC is only applicable to a very narrow range of maturity (EasyRo $<1.2 \%$ ), and gives higher values than those obtained from our hydrothermal experiments (Fig. 8 a). The differences between the two results become progressively smaller with the increasing extent of oil cracking with the values from $6-21 \%$ at EasyRo from $0.48-1.81 \%$ and from $2.5-6 \%$ at EasyRo from 1.81 to $3.0 \%$. Obviously, the $\left(1-C_{0} / C_{C}\right) \times 100 \%$ should be changed to $\left[1-C_{0} /\left(C_{c}-C_{\text {new }}\right.\right.$ gener $\left.)\right] \times 100 \%$ at $1.2 \%<$ EasyRo $<3.0 \%$, but the $\mathrm{C}_{\text {new gener }}$ is difficult to obtain. Fortunately, we find that the calculative EOC $\left(E O C 1=\left[1-C_{0} / C_{c}\right] \times 100\right)$ shows a good positive linear correlation with the actual EOC $\left(E O C 2=\left[1-M_{C} / M_{0}\right] \times 100\right)$ with equation of EOC2 $=1.2402 \times E O C 1-28.952$ and $R^{2}$ value of 0.9593 at EasyRo $<3.0 \%$ (Fig. 8b). This reveals that although Dahl's method may overestimate the extent of oil cracking, especially in highly cracked samples due to the new generation of 3- + 4-MD, the method can be corrected and new calculation formula can be used to reflect actual EOC.

The bridgehead-methylated diamondoids are thermodynamically more stable than other methylated diamondoid species ${ }^{33}$. On this basis, some diamondoid isomerization ratios (MAI, MDI, DMAI-1, DMAI-2, TMAl-1, TMAI-2, EAl, DMDI-1, DMDI-2) are used as maturity indicators. Figure 10a \& b shows that there is a good positive correlation between diamondoid isomerization ratios (EAI and DMDI-2) and EOC2 with regressive equations as follow, where EAI is applicable in the range of EasyRo $<1.81 \%$ (Fig. 10a).

$\mathrm{EAI}=0.0015 \mathrm{EOC} 2+0.2635 \mathrm{r}^{2}=0.6355($ EasyRo $<1.81 \%)(2)$

$\mathrm{DMDI}-2=0.0024 \mathrm{EOC} 2+0.3177 \mathrm{r}^{2}=0.7271(3)$

This implies that these parameters might help assess the extent of oil cracking (EOC2). Note that the isomerization ratio of DMDI-2 has a good correlation with EOC2 throughout the EasyRo range examined, indicating that it may be a reliable proxy for a wide range of maturity. 
On the other hand, the concentration ratios of diamondoid pairs are expected to eliminate the effect of matrix changes during the thermal cracking of oil. Some diamondoid concentration ratios (As/Ds, MAs/MDs, DMAs/DMDs, and DMAs/MDs) appear positively correlated with EOC2 at EasyRo from 0.48-2.1\% (Fig. 10c-f) with regressive equations as follow.

As/Ds $=0.0115$ EOC2 $+1.7478 r^{2}=0.6052($ EasyRo $<2.1 \%)(4)$

MAs/MDs $=0.0083$ EOC2 $+0.2543 r^{2}=0.8507($ EasyRo $<2.1 \%)(5)$

$\mathrm{DMAs} / \mathrm{MDs}=0.0131 \mathrm{EOC} 2+0.5355 \mathrm{r}^{2}=0.8054($ EasyRo $<2.1 \%)(6)$

DMAs/DMDs $=0.0225$ EOC2 $+0.8348 r^{2}=0.6159($ EasyRo $<2.1 \%)(7)$

However, the above diamondoid isomerization ratios negatively correlate with EasyRo values of $>2.1 \%$ when admantanesadamantanes enter the decomposition stage. The above equations established from hydrothermal pyrolysis are proposed to be used as proxies of the extent of oil cracking during $0.48-2.1 \%$ EasyRo for natural petroleum reservoirs.

\subsection{New generation of diamondoids and thiadiamondoids during TSR? 4.4.1. Occurrence of TSR in the experiments}

In pyrolysis experiments containing elemental $\mathrm{S}, \mathrm{MgSO}_{4}$ or $\mathrm{CaSO}_{4} \cdot 2 \mathrm{H}_{2} \mathrm{O}$ and $\mathrm{ZS} 1-\mathrm{L}$ oil, $\mathrm{H}_{2} \mathrm{~S}$ was generated and may have been derived from 1 ) cracking of ZS1-L oil, 2) elemental sulfur hydrolysis, 3) thermochemical reduction of $\mathrm{MgSO}_{4}$ or $\mathrm{CaSO}_{4} \cdot 2 \mathrm{H}_{2} \mathrm{O}$. The $\mathrm{H}_{2} \mathrm{~S}$ is not mainly from cracking of ZS1-L oil because thermal decomposition of ZS1-L oil with a sulfur content of $0.18 \%$ can only generate $0.056 \mathrm{mmol} / \mathrm{g} \mathrm{H}_{2} \mathrm{~S}$. Thus, $\mathrm{H}_{2} \mathrm{~S}$ must have mainly derived from the reduction of elemental $\mathrm{S}$ and $\mathrm{MgSO}_{4}$. Elemental S may react with water at temperatures as low as $200^{\circ} \mathrm{C}$ in the following disproportionation reaction $47,57,58$ :

$4 \mathrm{~S}+4 \mathrm{H}_{2} \mathrm{O} \rightarrow \mathrm{SO}_{4}{ }^{2-}+3 \mathrm{H}_{2} \mathrm{~S}+2 \mathrm{H}^{+}(8)$

An alternative production pathway for the exceptionally high yields of $\mathrm{H}_{2} \mathrm{~S}$ was via the classical aqueous reaction of elemental $\mathrm{S}$ and hydrocarbon shown in Eq. 9 (Orr, 1974; Schmid et al., 1987; Goldhaber and Orr, 1995; Seewald, 2003):

$4 \mathrm{~S}+1.33\left(-\mathrm{CH}_{2}-\right)+2.66 \mathrm{H}_{2} \mathrm{O} \rightarrow 4 \mathrm{H}_{2} \mathrm{~S}+1.33 \mathrm{CO}_{2}(9)$

The $\mathrm{H}_{2} \mathrm{~S} / \mathrm{S}^{0}$ molar ratio can be used to determine the amount of $\mathrm{H}_{2} \mathrm{~S}$ from the conversion of elemental S (Table 2). The $\mathrm{H}_{2} \mathrm{~S} / \mathrm{S}^{0}$ molar ratio based on Eq. 8 and Eq. 9 will approach 0.75 and 1, respectively. Group 1 experiment at the lowest temperature of $336{ }^{\circ} \mathrm{C}(0.57 \%$ EasyRo $)$ shows that nearly all $\mathrm{H}_{2} \mathrm{~S}$ was derived from elemental $\mathrm{S}$ as supported by the $\mathrm{H}_{2} \mathrm{~S} / \mathrm{S}^{0}$ molar ratio around 0.71 and by $\delta^{34} \mathrm{~S}_{\mathrm{H} 2 \mathrm{~S}}$ value of $-5 \%$ o (Table 2), which is close to that of elemental $\mathrm{S}$ (-6.3\%o). Furthermore, the increasing production of $\mathrm{CO}_{2}$ did not start until above $408^{\circ} \mathrm{C}$, when the $\mathrm{H}_{2} \mathrm{~S} / \mathrm{S}^{0}$ molar ratio began to be greater than 0.75 . This disconnect in thermal production implies $\mathrm{H}_{2} \mathrm{~S}$ was not produced via Eq. 8 from $336-384{ }^{\circ} \mathrm{C}\left(0.57-0.79 \%\right.$ EasyRo) in Group 1 . With the temperature increasing, the $\mathrm{H}_{2} \mathrm{~S} / \mathrm{S}^{0}$ molar ratio gradually increases until it reaches a maximum of 1.36 at $528^{\circ} \mathrm{C}(2.62 \%$ EasyRo), and then gradually decreases to 1.12 (Table 2$)$. Meanwhile, the $\delta^{34} \mathrm{~S}$ value of $\mathrm{H}_{2} \mathrm{~S}$ show rise from $-5 \%$ o to $-2.45 \%$, getting closer to the $\delta^{34} \mathrm{~S}$ value of $\mathrm{MgSO}_{4}\left(\delta^{34} \mathrm{~S}\right.$ of $+3.75 \%$ ), suggesting that the $\mathrm{H}_{2} \mathrm{~S}$ may have significantly derived from the reduction of $\mathrm{MgSO}_{4}$ in the aqueous experiments with reaction as follows:

$\mathrm{SO}_{4}^{2-}+2 \mathrm{H}^{+}+\mathrm{CH}_{4} \rightarrow \mathrm{CO}_{2}+\mathrm{H}_{2} \mathrm{~S}+2 \mathrm{H}_{2} \mathrm{O}(10)$

It can be expected that with the increase of temperature, more $\mathrm{MgSO}_{4}$ was involved in TSR reaction, or TSR has proceeded to higher degrees. If $\mathrm{S}$ can react with hydrocarbons to release $\mathrm{H}_{2} \mathrm{~S}$ without generation of $\mathrm{SO}_{4}{ }^{2-}$, the molarity of elemental $\mathrm{S}$ is about $12.79 \mathrm{mmol}(26.8 \mathrm{mg})$, which is lower than $\mathrm{H}_{2} \mathrm{~S}$ from $504^{\circ} \mathrm{C}$ to $600^{\circ} \mathrm{C}$. Hence, the conversion of elemental $\mathrm{S}$ is insufficient for the generation of $\mathrm{H}_{2} \mathrm{~S}$ from $504^{\circ} \mathrm{C}$ to $600^{\circ} \mathrm{C}$. $\mathrm{MgSO}_{4}$ was involved in the reaction. Moreover, calculation of all $103 \mathrm{mg} 12.86 \mathrm{mmol} / \mathrm{g} \mathrm{MgSO}_{4}$ and $26.8 \mathrm{mg} 12.79 \mathrm{mmol} / \mathrm{g}$ elemental sulfur in the experiment is $25.8865 \mathrm{mmol} / \mathrm{g} \mathrm{H} \mathrm{S}_{2}$, which is much higher than the maximum yield of $\mathrm{H}_{2} \mathrm{~S}(17.43 \mathrm{mmol} / \mathrm{g})$ occurs at $528{ }^{\circ} \mathrm{C}$. The yield of $\mathrm{H}_{2} \mathrm{~S}$ and the low magnitude of the influence of $\mathrm{MgSO}_{4}$ on the $\delta^{34} \mathrm{~S}_{\mathrm{H} 2 \mathrm{~S}}$ confirm that only limited amounts of $\mathrm{MgSO}_{4}$ were involved in the TSR reactions. Some early formed $\mathrm{H}_{2} \mathrm{~S}$ would be expected to react with hydrocarbons to form OSCs such as thiols, (poly)sulfides, thiophenes, and benzothiophenes ${ }^{59,60}$, thus $\mathrm{H}_{2} \mathrm{~S}$ shows a decreasing trend at EasyRo $=2.5-3.87 \%$ (Table 2).

However, Group 2 experiments are reactions between elemental $\mathrm{S}$ and hydrocarbons with no $\mathrm{CaSO}_{4} \cdot 2 \mathrm{H}_{2} \mathrm{O}$ involved. Firstly, the maximum value of the $\mathrm{H} 2 \mathrm{~S} / \mathrm{SO}$ molar ratio in Group 2 is around 0.9 at the first EasyRo $=1.13$ and then slightly decreases from 0.93 to 0.65 with EasyRo from $1.13 \%$ to $1.69 \%$. Secondly, the $\delta^{34} \mathrm{~S}$ of $\mathrm{H}_{2} \mathrm{~S}$ generated in Group 2 ranged from $-5.79 \%$ o to $-6.79 \%$, within $\pm 1 \%$ o of elemental $\mathrm{S}(-6.3 \%$ o). Finally, Group 2 produced a very high amount of $\mathrm{CO}_{2}\left(1.71 \mathrm{mmol} / \mathrm{g}\right.$ at $1.13 \%$ EasyRo) at the first desired time compared to the meager yields produced by Group 1 above $360^{\circ} \mathrm{C}(\mathrm{Table} 2)$. This indicates $\mathrm{H}_{2} \mathrm{~S}$ was created via the classical aqueous reaction of elemental $\mathrm{S}$ and hydrocarbon shown in Eq. 9. Moreover, the presence of elemental $\mathrm{S}$ can accelerate the rate of hydrocarbon thermal chemical alteration (TCA) due to organic sulfur compounds (e.g., thiols and sulfides) that form through the reaction of $\mathrm{H}_{2} \mathrm{~S}$ or polysulfides with hydrocarbons and subsequently thermally degrade leading to the formation of sulfur radicals that in turn enhance TCA reactions ${ }^{61}$.

Therefore, it can be concluded that the positive $\delta^{34} \mathrm{~S}$ value of $\mathrm{H}_{2} \mathrm{~S}$ and the increase of $\mathrm{CO}_{2}$ and $\mathrm{H}_{2} \mathrm{~S} / \mathrm{S}^{0}$ molar ratio for the Group 1 experiments, as shown in Table 2, may be ascribed to the TSR reaction between sulfate and hydrocarbons at elevated temperature rather than the reaction between hydrocarbons and 
$\mathrm{H}_{2} \mathrm{~S}$ or elemental sulfur, as shown Group 2 experiments. Here, TSR experiments represent Group1 experiments in this study.

\subsubsection{Generation of diamondoids during TSR}

The presence of TSR reaction significantly increases the yield of diamantanes relative to the blank non-TSR experiments (Fig. 5). Here, at $1.47 \%$ EasyRo (456 $\left.{ }^{\circ} \mathrm{C}\right)$, a higher yield of diamantanes detected in the TSR system $(218.94 \mu \mathrm{g} / \mathrm{g})$ was higher than that of the thermal chemical alteration (TCA) (only $\left.156.07 \mu \mathrm{g} / \mathrm{g}\right)$, indicating that diamantanes must have newly generated during TSR (Fig. 5a). On the other hand, the TSR reaction accelerates the generation of diamantanes comparing with TCA (Fig. 5a). For example, diamantanes are shown to be predominantly generated in the EasyRo range of $0.57-1.81 \%$ with maximum yields of $240 \mu \mathrm{g} / \mathrm{g}$ at 1.81 EasyRo that is before TCA experiments that much lower diamantanes yields of $72.74 \mu \mathrm{g} / \mathrm{g}$ at $0.79 \%$ EasyRo to $182.1 \mu \mathrm{g} / \mathrm{g}$ of $3.1 \%$ (Fig. 2). Elemental S can substantially lower the onset temperature of hydrocarbon thermal chemical alteration and appears to reduce the activation energy of lowsulfur oil thermal chemical alteration by approximately $92 \mathrm{~kJ} \mathrm{~mol}^{-1} 61$. The observed acceleration of diamantanes generation is possibly due to sulfur-derived radical species or $\mathrm{H}_{2} \mathrm{~S}$ formed via TSR or disproportionation reaction that enhances the formation of diamantanes.

Furthermore, diamantanes show a rapid decrease after the maximum yields at EasyRo $>1.81 \%$ (Fig. 5a), which is significantly lower than that (EasyRo $>3.0 \%$ ) of thermal chemical alteration (TCA) (Fig. 2). Similarly, diamantanes remain stable at up to $550{ }^{\circ} \mathrm{C}$ during TCA while the temperature is $480{ }^{\circ} \mathrm{C}$ during TSR at the same heating rates of $20^{\circ} \mathrm{C} / \mathrm{h}$ (Fig. $5 \mathrm{~d}$ ). This result may be due to the catalysis of $\mathrm{S}$ radical (i.e., from $\mathrm{H}_{2} \mathrm{~S}$ ), which can accelerate the decomposition of $\mathrm{HC}$ or OM.

The mechanism for generating diamondoids during TSR may be through free radical reactions, a mechanism similar to their generation from high temperature cracking of alkanes during the experiment simulation ${ }^{62,63}$. Consequently, we considered that the sulfur-derived radical species or $\mathrm{H}_{2} \mathrm{~S}$ during TSR have a facilitative effect on the cleavage of high molecular-mass fractions, resulting in the new generation of diamondoids from TSR experiments in the present study. Meanwhile, hydrogen exchange between water and organic matter also proceeds via sulfur-derived radical species (i.e., from $\mathrm{H}_{2} \mathrm{~S}$ ) ${ }^{50}$, leading to demethylation and isomerization of hydrocarbon to form diamondoids. Briefly, TSR can lead to the generation of diamondoids through free radical reactions.

\subsubsection{Generation of thiadiamondoids during TSR}

Thiadiamondoids are diamond-like compounds with a sulfide bond located within the cage structure (Fig. 1), and were suggested to be formed from reactions of adamantanes with sulfur species ${ }^{64}$. Thiaadmantane and methyl thiaadmantanes isomers were detected at $1.81 \%$ EasyRo when the yields of diamantanes reached a maximum value during the hydrothermal pyrolysis of ZS1-L oil under TSR condition (Fig. 1). To our knowledge, this is the first successful laboratory synthesis of thiaadmantanes from a petroleum sample via TSR. Although previous laboratory experiments have successfully synthesized thiaadmantanes, thiaadmantanes were only detected from reactions of reduced $\mathrm{S}$ or $\mathrm{CaSO}_{4}$ with pure diamondoids ${ }^{64,65}$. Based on these laboratory experiments, Wei et al. $(2007 b)^{64}$ proposed that diamondoids appear to be the only precursors of thiaadmantanes during TSR (Fig. 11a). However, our results indicate that thiaadmantanes and diamondoids may have been generated simultaneously, likely not via reactions with diamondoids based on the following aspects (Fig. 11). Firstly, during TSR experiments at EasyRo of $1.81 \%$, both diamantanes and corresponding thiaamantanes were formed, and thiadamantanes show positive correlations with the corresponding diamantanes (2-TA vs D; M-2-TA vs MD; DM-2-TA vs DMD; TM-2-TA vs TMD) from (Fig. 12a \&b) with a higher yield of diamantanes during TSR compared with hydrothermal pyrolysis or anhydrous pyrolysis (Fig. 12a). The experimental results indicate that diamondoids and thiadamantanes may have been formed simultaneously, which is consistent with case studies showing the positive relationships between diamondoids and thiadiamondoids concentrations from oils and condensates from the Tarim Basin and Gulf of Mexico Basin ${ }^{25,49}$. In contrast, if diamondoids are the only precursor of thiaadamantane ${ }^{64}$, conversion of significant amounts of diamondoids to thiaadmantanes may lead to a negative correlation between the yields of diamondoids and thiaadmantanes. Secondly, $\mathrm{C}-\mathrm{C}$ bonds in the cage structure of diamondoids have been proposed to be hard to break up due to their thermal stability ${ }^{30-32}$, it is more energy-favorable to form thiaadamantanes from other non-cage compounds. Thus, it is reasonable for thiaadamantanes to have been generated during the formation of diamondoids. Considering that diamondoids can be generated from pyrolysis of all four fractions ${ }^{13-16}$, a nondiamondoid source of thiaadamantanes is proposed here as shown in Fig. 11b.

However, thiaadmantanes only form at $1.81 \%$ EasyRo $\left(480{ }^{\circ} \mathrm{C}\right)$ not at other experiments from $336{ }^{\circ} \mathrm{C}$ to $600{ }^{\circ} \mathrm{C}$, under the TSR condition. One possible explanation is that thiaadamantanes are formed in relatively high-temperature conditions and are expected to decompose higher EasyRo. Xiao et al. (2019) ${ }^{66}$ proposed that thiaadamantanes show slight to moderate cracking at EasyRo of $1.81 \%$ and thus have far less thermally stable than diamondoids. Similarly, thiadiamondoids were found to be thermally degraded at temperatures $>180^{\circ} \mathrm{C}$ in TSR-altered oils from the Smackover and Norphlet formations of the US Gulf of Mexico ${ }^{49,67}$. The reservoir temperatures of $180{ }^{\circ} \mathrm{C}$ can correspond to the equivalent vitrinite reflectance values of about $1.9 \%$ based on the thermal history of the Norphlet Sandstone in Mobile Bay, northern Gulf of Mexico ${ }^{68}$. Our TSR experimental results are generally consistent with this field observation. Another possible explanation is the difficulty of detecting thiaadmantanes due to low concentrations and loss during the complex sample preparation.

Notably, TSR resulted in the new generation of diamondoids (Fig. 5), and thus had a significant effect on the distribution and concentration of diamondoids. Thus, in TSR-altered oils, diamondoid-related maturity proxies have been altered significantly (Table 3), and thus cannot be used to indicate EOC.

\section{Conclusions}

Based on our experiments, we can conclude that:

(1) Hydrothermal pyrolysis experiments indicate that water can enhance the yields of diamondoids. Total diamondoids may have mainly generated in $0.48 \%$ 2.1\% EasyRo and decomposed at > 2.1\% EasyRo. Especially, diamantanes show decomposition at > 3.0\% EasyRo. 
(2) MDI, EAl, DMAl-1, DMDI-2 are shown to be reliable maturity proxies at maturity over ca.1.0\% EasyRo, and TMAl-1, TMAl-2 and DMAI-2 can only be used to reflect the higher maturity at EasyRo $>2.0 \%$.

(3) The extents of oil cracking (EOC) calculated from Dahl's 3-+4-MD method are higher than the actual values, especially for highly mature samples due to their new generation, but can be obtained using our correction formula (EOC2 $=1.2402 \times E O C 1-28.952)$ at EasyRo $<3.0 \%$.

(4) EAI, DMDI-2, As/Ds, MAs/MDs, DMAs/DMDs, and DMAs/MDs can serve as molecular proxies to estimate the extent of oil cracking at EasyRo mainly < $2.1 \%$.

(5) TSR is found to newly generate diamantanes at $<1.81 \%$ EasyRo followed by their decomposition, while the decomposition of diamantanes by TCA occurs at $>3.0 \%$ EasyRo, and thus any diamondoid-related proxy cannot be used to reflect maturity and EOC.

(6) Thiaadamantanes were generated from an experiment of TSR by oil at $1.81 \%$ EasyRo for the first time, likely via pyrolysis of non-cage structure hydrocarbons.

Our results provide crucial experimental evidence for understanding the evolution of diamondoids during thermal maturity and TSR reactions under natural conditions.

\section{Declarations}

\section{ACKNOWLEDGEMENTS}

This work has been financially supported by the National Natural Science Foundation of China (Grant Nos. 41730424 and 4181101560 ). The authors are very grateful to Dr. Yongqiang Xiong for providing the HD23 oil sample and his valuable suggestion in improving work. We also thank Dr. Wenmin Jiang and Dr. Yun Li for their help with GC-MS-MS analysis and pyrolysis experiments.

\section{Author contributions}

Yanyan Peng: Data curation, Writing- Original draft preparation, Validation.

Chunfang Cai: Writing- Reviewing and Editing, Validation, Supervision.

Chenchen Fang, Liangliang Wu: Investigation, Conceptualization.

Jinzhong Liu, Peng Sun, Dawei Liu: Methodology, Data curation

\section{References}

1. Landa, S. Adamantane and its derivatives. Ropa a Uhlie, 1, 5-7 (1959).

2. Petrov, A., Arefjev, O. A. \& Yakubson, Z. V.. Hydrocarbons of adamantane series as indices of petroleum catagenesis process. In Advances in Organic Geochemistry 1973 (eds. B. Tissot and F. Bienner).Editions Technip, Parispp.517-522. (1974).

3. McKervey, M. A. Synthetic approaches to large diamondoid hydrocarbons., 36, 971-992 (1980).

4. Wingert, W. S. GC-MS analysis of diamondoid hydrocarbons in Smackover petroleums., 71, 37-43 (1992).

5. Dahl, J. E. et al. Diamondoid hydrocarbons as indicators of oil cracking. Nature, 399, 54-56 (1999).

6. Dahl, J. E., Liu, S. G. \& Carlson, R. M. K. Isolation and structure of higher diamondoids, nanometer-sized diamond molecules., 299, 96-99 (2003).

7. Wei, Z. B., Moldowan, J. M., Jarvie, D. M. \& Hill, R. The fate of diamondoids in coals and sedimentary rocks., 34, 1013-1016 (2006a).

8. Wei, Z. B., Moldowan, J. M. \& Paytan, A. Diamondoids and molecular biomarkers generated from modern sediments in the absence and presence of minerals during hydrous pyrolysis. Org. Geochem, 37, 891-911 (2006b).

9. Schulz, L. K., Wilhelms, A., Rein, E. \& Steen, A. S. Application of diamondoids to distinguish source rock facies. Org. Geochem, 32, 365-375 (2001).

10. Wei, Z. B. et al. Diamondoid hydrocarbons as a molecular proxy for thermal maturity and oil cracking: geochemical models from hydrous pyrolysis. Org. Geochem, 38, 227-249 (2007a).

11. Fort, R. C. \& Schleyer, P. R. Adamantane: consequences of the diamondoid structure. Chem. Rev, 64, 277-300 (1964).

12. Lin, R. \& Wilk, Z. A. Natural occurrence of tetramantane $(\mathrm{C} 22 \mathrm{H} 28)$, pentamantane $(\mathrm{C} 26 \mathrm{H} 32)$ and hexamantane $(\mathrm{C} 30 \mathrm{H} 36)$ in a deep petroleum reservoir., 74 , 1512-1521 (1995).

13. Fang, C. C., Xiong, Y. Q., Liang, Q. Y. \& Li, Y. Variation in abundance and distribution of diamondoids during oil cracking. Org. Geochem, 47, 1-8 (2012).

14. Giruts, M. V., Rusinova, G. V. \& Gordadze, G. N. Generation of adamantanes and diamantanes by thermal cracking of high-molecular-mass saturated fractions of crude oils of different genotypes. Pet. Chem, 46, 225-236 (2006).

15. Giruts, M. V. \& Gordadze, G. N. Generation of adamantanes and diamantanes by thermal cracking of polar components of crude oils of different genotypes. Pet. Chem, 47, 12-22 (2007).

16. Fang, C. C. et al. Peng PA.The origin and evolution of adamantanes and diamantanes in petroleum. Geochim. Cosmochim. Acta, 120, 109-120 (2013).

17. Goldhaber, M. B. \& Orr, W. L. Kinetic controls on thermochemical sulfate reduction as a source of sedimentary H2S, in: M.A. Vainravamurth, M.A.A. Schoonen (Eds.), Geochemical Transformations of Sedimentary Sulfur, ACS Symposium Series vol. 612, pp. 412-625(1995).

Page $11 / 22$ 
18. Berwick, L., Alexander, R. \& Pierce, K. Formation and reactions of alkyl adamantanes in sediments: Carbon surface reactions. Org. Geochem, 42 (7), 752761 (2012).

19. Siskin, M., Bron, G., Katritzky, A. R. \& Balasubramanian, M. Aqueous organic chemistry. 1. Aquathermolysis: comparison with thermolysis in the reactivity of aliphatic compounds. Energy Fuels, 4, 475-482 (1990).

20. Price, L. C. Thermal stability of hydrocarbons in nature: limits, evidence, characteristics, and possible controls. Geochim. Cosmochim. Acta, 57, 32613280 (1993).

21. Seewald, J. S., Benitez-Nelson, B. C. \& Whelan, J. K. Laboratory and theoretical constraints on the generation and composition of natural gas. Geochim. Cosmochim. Acta, 62, 1599-1617 (1998).

22. Schimmelmann, A., Lewan, M. D. \& Wintsch, R. P. D/H isotope ratios of kerogen, bitumen, oil, and water in hydrous pyrolysis of source rocks containing kerogen types I, II, IIS, and III. Geochim. Cosmochim. Acta, 63, 3751-3766 (1999).

23. Lewan, M. D. Experiments on the role of water in petroleum formation. Geochim. Cosmochim. Acta, 61, 3691-3723 (1997).

24. Lewan, M. D. \& Roy, S. Role of water in hydrocarbon generation from Type-I kerogen in Mahogany oil shale of the Green River Formation. Org. Geochem, 42, 31-41 (2011).

25. Cai, C. F. et al. The effect of thermochemical sulfate reduction on formation and isomerization of thiadiamondoids and diamondoids in the Lower Paleozoic petroleum pools of the Tarim Basin, NW China. Org. Geochem, 101, 49-62 (2016b).

26. Orr, W. L. Changes in sulfur content and isotopic ratios of sulfur during petroleum maturation-study of Big Horn Basin Paleozoic Oils. Am. Assoc. Pet. Geol. Bull, 58, 2295-2318 (1974).

27. Krouse, H. R., Viau, C. A., Eliuk, L. S., Ueda, A. \& Halas, S. Chemical and isotopic evidence of thermochemical sulphate reduction by light hydrocarbon gases in deep carbonate reservoirs. Nature, 333, 415-419 (1988).

28. Cai, C. F., Worden, R. H., Bottrell, S. H., Wang, L. S. \& Yang, C. C. Thermochemical sulphate reduction and the generation of hydrogen sulphide and thiols (mercaptans) in Triassic carbonate reservoirs from the Sichuan Basin, China. Chem. Geol, 202, 39-57 (2003).

29. Cai, C. F. et al. Sulfur isotopic compositions of individual organosulfur compounds and their genetic links in the Lower Paleozoic petroleum pools of the Tarim Basin, NW China. Geochim. Cosmochim. Acta, 182, 88-108 (2016a).

30. Chen, J. H., Fu, J. M., Sheng, G. Y., Liu, D. H. \& Zhang, J. J. Diamondoid hydrocarbon ratios: novel maturity indices for highly mature crude oils. Org. Geochem, 25, 179-190 (1996).

31. Li, J. G., Philp, P. \& Cui, M. Z. Methyl diamantane index (MDI) as a maturity parameter for Lower Palaeozoic carbonate rocks at high maturity and overmaturity. Org. Geochem, 31, 267-272 (2000).

32. Zhang, S. C., Huang, H. P., Xiao, Z. Y. \& Liang, D. G. Geochemistry of Palaeozoic marine petroleum from the Tarim Basin, NW China: Part 2. Maturity assessment. Org. Geochem, 36, 1215-1225 (2005).

33. Clark, T., Knox, T. M., McKervey, M. A., Mackle, H. \& Rooney, J. J. Thermochemistry of bridgehead-ring substances. Enthalpies of formation of some diamondoid hydrocarbons and perhydroquinacene. Comparisons with data from empirical force field calculations. J. Am. Chem. Soc, 101, 2404-2410 (1979).

34. Grice, K., Alexander, R. \& Kagi, R. I. Diamondoid hydrocarbon ratios as indicators of biodegradation in Australian crude oils. Org. Geochem, 31, 67-73 (2000).

35. Sweeney, J. J. \& Burnham, A. K. Evaluation of a simple model of vitrinite reflectance based on chemical-kinetics. Am. Assoc. Pet. Geol. Bull, 74, 15591570 (1990).

36. Zhang, T. W., Amrani, A., Ellis, G. S., Ma, Q. S. \& Tang, Y. C. Experimental investigation on thermochemical sulfate reduction by H2S initiation. Geochim. Cosmochim. Acta, 72 (14), 3518-3530 (2008).

37. Saccocia, P. J. \& Seyfried, W. E. Talc-quartz equilibria and the stability of magnesium-chloride complexes in $\mathrm{NaCl}-\mathrm{MgCl} 2$ solutions at $300 \mathrm{C}$, and $350 \mathrm{C}$, and 400 C, 500 bars. Geochim. Cosmochim. Acta, 54 (12), 3283-3294 (1990).

38. Seewald, J. S., Eglinton, L. B. \& Ong, Y. L. An experimental study of organic-inorganic interactions during vitrinite maturation. Geochim. Cosmochim. Acta, 64 (9), 1577-1591 (2000).

39. Zhang, T. W., Ellis, G. S., Ma, Q., Amrani, A. \& Tang, Y. Kinetics of uncatalyzed thermochemical sulfate reduction by sulfur-free paraffin. Geochim. Cosmochim. Acta, 96, 1-17 (2012).

40. Heydari, E. \& Moore, C. H. Burial diagenesis and thermochemical sulfate reduction, Smackover Formation, southeast Mississippi salt basin., 17, 10801084 (1989).

41. Machel, H. G. Saddle dolomite as a by-product of chemical compaction and thermochemical sulfate reduction., 15, 936-940 (1987).

42. Manzano, B. K., Fowler, M. G. \& Machel, H. G. The influence of thermochemical sulfate reduction on hydrocarbon composition in Nisku reservoirs, Brazeau River area, Alberta, Canada, Org. Geochem, 27, 507-521 (1997).

43. Worden, R. H., Smalley, P. C. \& Oxtoby, N. H. The effects of thermal sulfate reduction upon formation water salinity and oxygen isotopes in carbonate gas reservoirs, Geochim. Cosmochim. Acta, 60, 3925-3931 (1996).

44. Worden, R. H., Smalley, P. C. \& Oxtoby, N. H. Gas souring by thermochemical sulfate reduction at $140^{\circ} \mathrm{C}$. AAPG Bull, 79, 854-863 (1995).

45. Kiyosu, Y. \& Krouse, H. R. Thermochemical reduction and sulfur behavior of sulfate by acetic acid in the presence of native sulfur. Geochem. J, 27, 49-57 (1993). 
46. Cross, M. M., Manning, D. A. C., Bottrell, S. H. \& Worden, R. H. Thermchemical sulphate reduction (TSR): experimental determination of reaction kinetics and implications of the observed reaction kinetics and implications of the observed reaction rates for petroleum reservoirs. Org. Geochem, 35, 393-404 (2004).

47. Toland, W. G. Oxidation of organic compounds with aqueous sulphate. J. Am. Chem. Soc, 82, 1911-1916 (1960).

48. Liang, Q. Y., Xiong, Y. Q., Fang, C. C. \& Li, Y. Quantitative analysis of diamondoids in crude oils using gas chromatography - triple quadrupole mass spectrometry. Org. Geochem, 43, 83-91 (2012).

49. Wei, Z. B. et al. Thiadiamondoids as proxies for the extent of thermochemical sulfate reduction. Org. Geochem, 44, 53-70 (2012).

50. Leif, R. N. \& Simoneit, B. R. T. The role of alkenes produced during hydrous pyrolysis of a shale. Org. Geochem, 31, 1189-1208 (2000).

51. Jiang, W. M., Li, Y. \& Xiong, Y. Q. The effect of organic matter type on formation and evolution of diamondoids. Mar. Pet. Geol, 89, 714-720 (2018).

52. Li, Y. et al. Origin of adamantanes and diamantanes in marine source rock. Energy Fuels, 29, 8188-8194 (2015).

53. Tang, Y., Jenden, P. D., Nigrini, A. \& Teerman, S. C. Modeling early methane generation in coal. Energy Fuels, 10 (3), $659-671$ (1996).

54. Schimmelmann, A., Sessions, A. L. \& Mastalerz, M. Hydrogen isotopic (D/H) composition of organic matter during diagenesis and thermal maturation. Annu. Rev. Earth Planet. Sci, 34, 501-533 (2006).

55. Li, Y. et al. The application of diamondoid indices in the Tarim oils. Am. Assoc. Pet. Geol. Bull, 101, 267-291 (2018).

56. Takach, N. E., Barker, C. \& Kemp, M. K. Stability of natural gas in the deep subsurface: thermodynamic calculation of equilibrium compositions. Am. Assoc. Pet. Geol. Bull, 71, 322-333 (1987).

57. Robinson, B. W. Sulphur isotope equilibrium during sulphur hydrolysis at high temperatures. Earth Planet. Sci. Lett, 18, $443-450$ (1973).

58. Said-Ahmad, W., Amrani, A. \& Aizenshtat, Z. The action of elemental sulfur plus water on 1-octene at low temperatures. Org. Geochem, 59, 82-86 (2013).

59. Krein, E. B. \& Aizenshtat, Z. 1995. Proposed thermal pathways for sulfur transformations in organic macromolecules: Laboratory simulation experiments. In Geochemical Transformations of Sedimentary Sulfur (eds. M. A. Vairavamurthy and M. A. A. Schoonen).American Chemical Society, Washington DC,pp. 110-137.

60. Nguyen, V. P., Burkle'-Vitzthum, V., Marquaire, P. M. \& Michels, R. Thermal reactions between alkanes and H2S or thiols at high pressure. J. Anal. Appl. Pyrol, 103, 307-319 (2013).

61. Ellis, G. S., Zhang, T. W., Kralert, P. G. \& Tang, Y. C. Kinetics of elemental sulfur reduction by petroleum hydrocarbons and the implications for hydrocarbon thermal chemical alteration. Geochim. Cosmochim. Acta, 251, 192-216 (2019).

62. Gordadze, G. N. \& Giruts, M. V. Synthesis of adamantine and diamantine hydrocarbons by high-temperature cracking of higher n-alkanes. Pet. Chem, $\mathbf{4 8 ,}$ 414-419 (2008).

63. Dahl, J. E. et al. Synthesis of higher diamondoids and implications for their formation in petroleum. Angew. Chem., Int. Ed, 49, 9881-9885 (2010).

64. Wei, Z. B. et al. Origins of thiadiamondoids and diamondoidthiols in petroleum. Energy Fuels, 21 (6), 3431-3436 (2007b).

65. Gvirtzman, Z. et al. Compound-specific sulfur isotope analysis of thiadiamondoids of oils from the Smackover Formation, USA. Geochim. Cosmochim. Acta, 167, 144-161 (2015).

66. Xiao, Q. L., Sun, Y. G., He, S., Liu, J. Z. \& Zhu, C. S. Thermal stability of 2-thiadiamondoids determined by pyrolysis experiments in a closed system and its geochemical implications. Org. Geochem, 130, 14-21 (2019).

67. Walters, C. C. et al. Petroleum alteration by thermochemical sulfate reduction - a comprehensive molecular study of aromatic hydrocarbons and polar compounds. Geochim. Cosmochim. Acta, 153, 37-71 (2015).

68. Mankiewicz, P. J., Pottorf, R. J., Kozar, M. G. \& Vrolijket, P. Gas geochemistry of the Mobile Bay Jurassic Norphlet Formation: thermal controls and implications for reservoir connectivity. Am. Assoc. Pet. Geol. Bull, 93, 1319-1346 (2009).

\section{Figures}




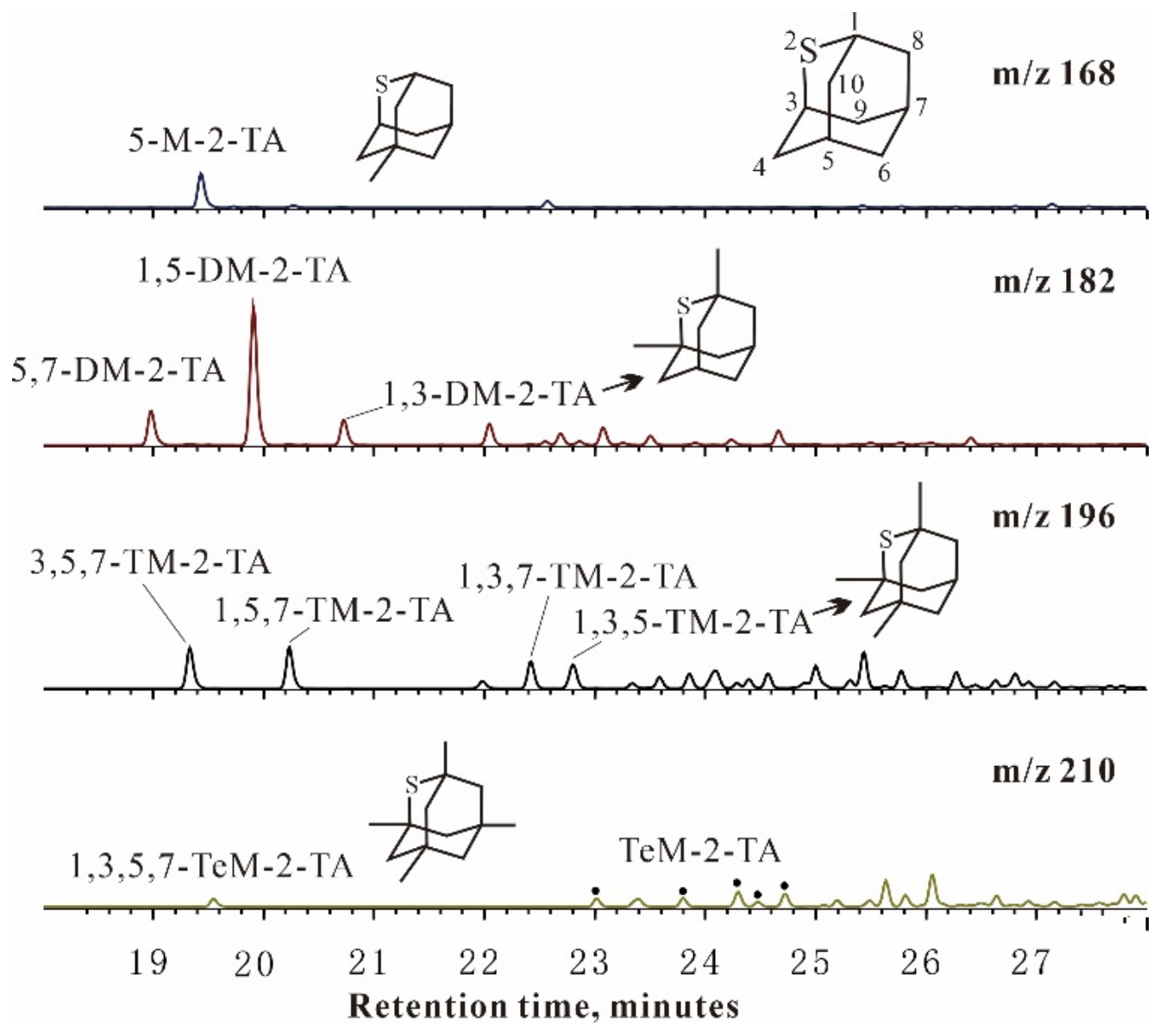

Figure 1

Mass chromatograms of alkylated thiadiamantanes in the sulfidic fraction of the products from TSR experiments (Group1) at $480{ }^{\circ} \mathrm{C} .5-\mathrm{M}-2-\mathrm{TA}=5$-methyl-2thiaadmantane; 5,7-DM-2-TA = 5,7-dimethyl-2-thiaadmantane; 1,5-DM-2-TA= 1,5-dimethyl-2-thiaadmantane; 1,3-DM-2-TA= 1,3-dimethyl-2-thiaadmantane; 3,5,7$\mathrm{TM}-2-\mathrm{TA}=3,5,7$-trimethyl-2-thiaadmantane; 1,5,7-TM-2-TA= 1,5,7-trimethyl-2-thiaadmantane; 1,3,7-TM-2-TA= 1,3,7-trimethyl-2-thiaadmantane; 1,3,5-TM-2-TA= 1,3,5-trimethyl-2-thiaadmantane; 1,3,5,7-TeM-2-TA = 1,3,5,7-tetramethyl-2-thiaadmantane; TeM-2-TA= tetramethyl-2-thiaadmantane.

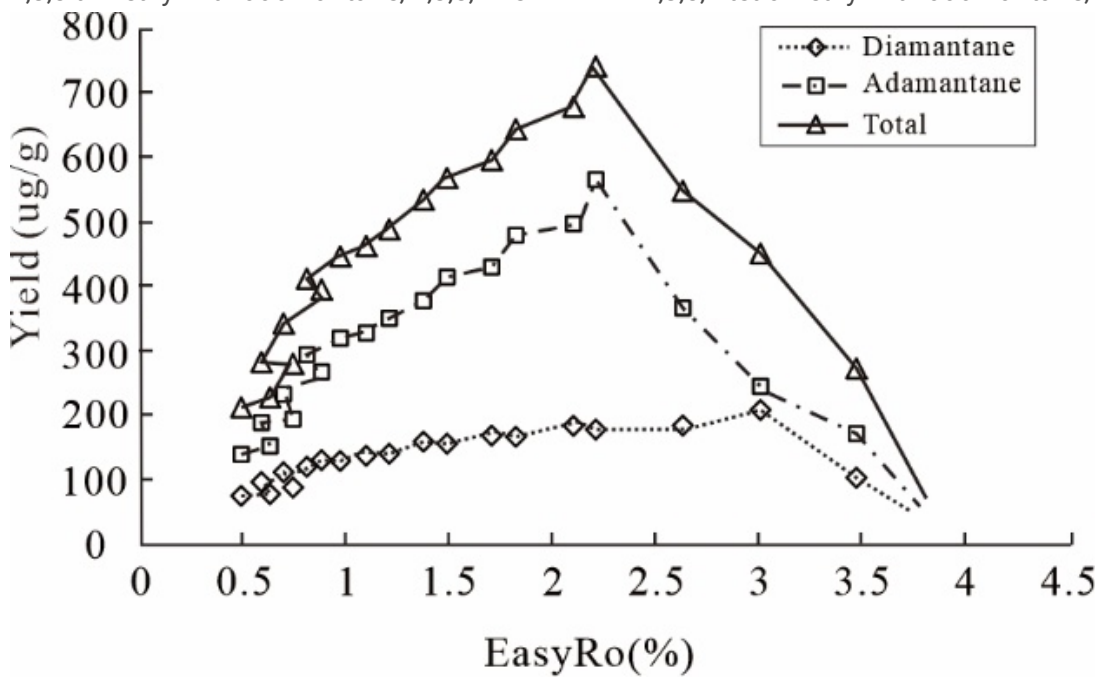

Figure 2

Variation in diamondoids yields ( $\mu \mathrm{g} / \mathrm{g}$ oil) with EasyRo $(\%)$ from hydrothermal pyrolysis of oil. (Total = sum of adamantanes and diamantanes) 

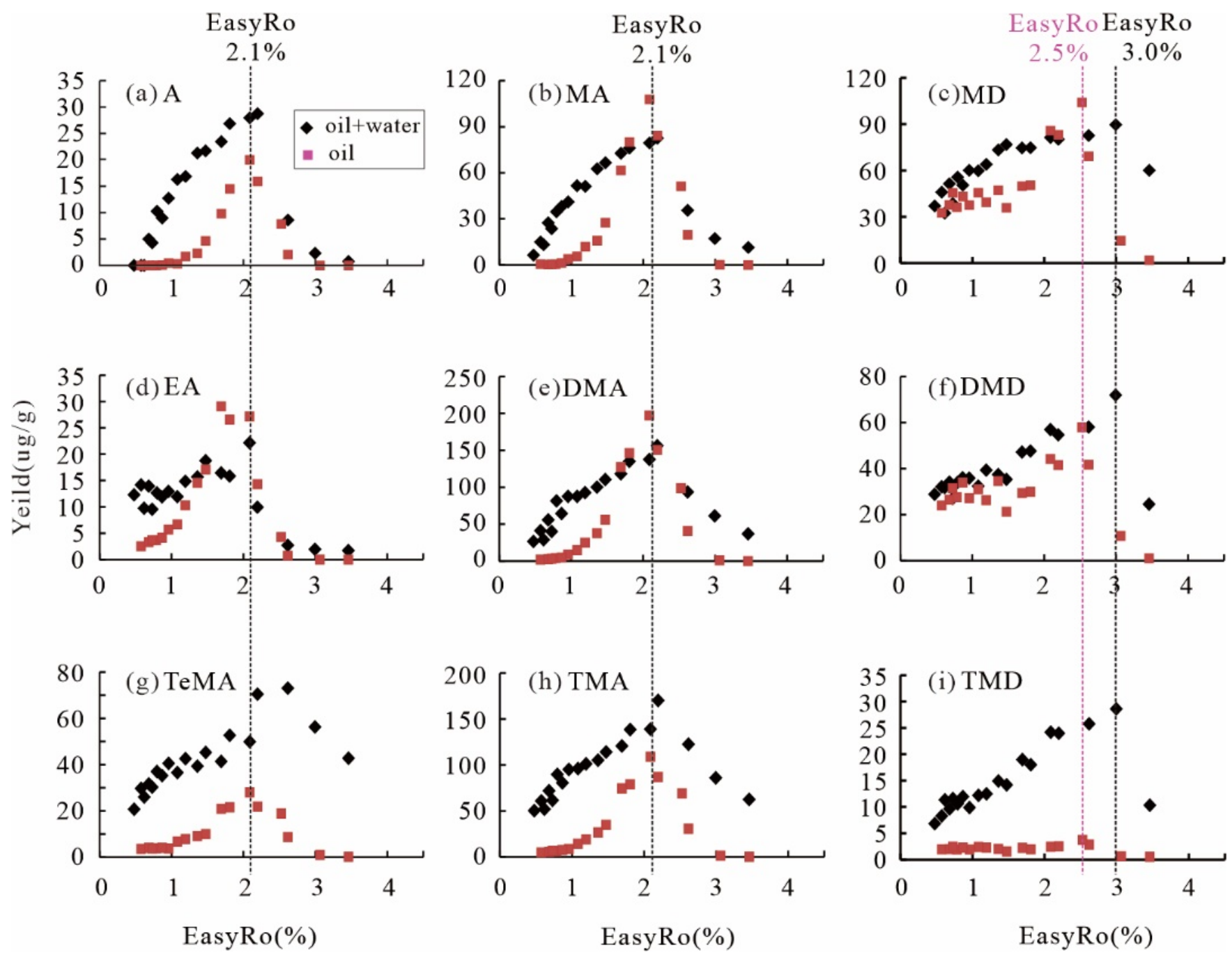

Figure 3

Variation in the yields ( $\mu \mathrm{g} / \mathrm{g}$ oil) of different types of diamondoids generated from hydrothermal and Fang et al. (2012)'s anhydrous pyrolysis of oil with EasyRo (\%): (a) A = adamantanes, (b) MA = methyladamantanes, (c) MD = methyldiamantanes, (d) EA = ethyladamantanes, (e) DMA = dimethyladamantanes,

(f) $\mathrm{DMD}=$ dimethyldiamantanes, $(\mathrm{g})$ TeMA = Tetramethyladamantane, (h) TMA = trimethyladamantanes, (i) TMD = trimethyldiamantanes.
$\delta^{34} \mathrm{~S}_{\mathrm{S} 0}=-6.3 \%$
$\delta^{34} \mathrm{~S}_{\mathrm{MgSO} 4}=+3.74 \%$

œ

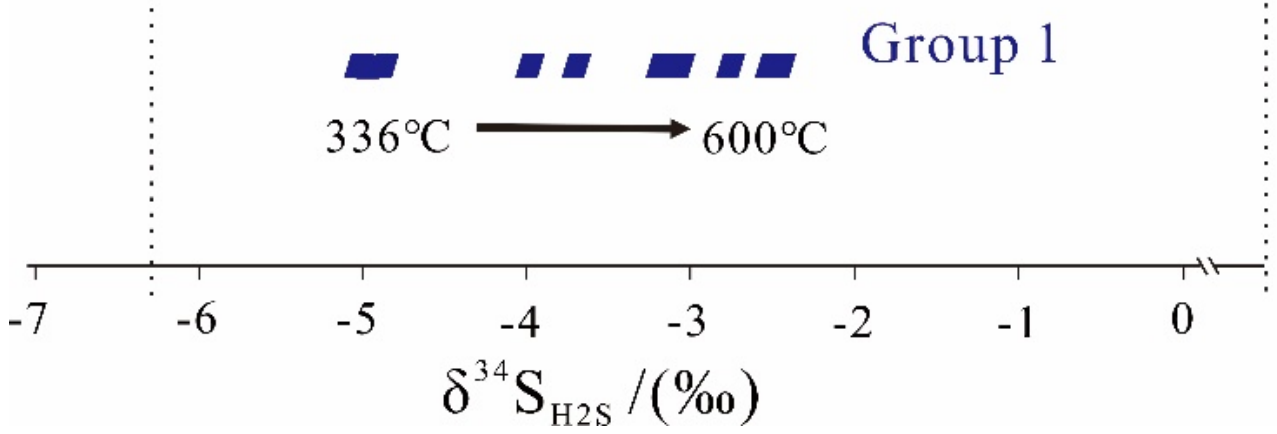

Figure 4

The 34S isotopic ratios of $\mathrm{H} 2 \mathrm{~S}$ in hydrothermal experiments involving SO, MgSO 4 and $\mathrm{CaSO} 4 \cdot 2 \mathrm{H} 2 \mathrm{O}$. 

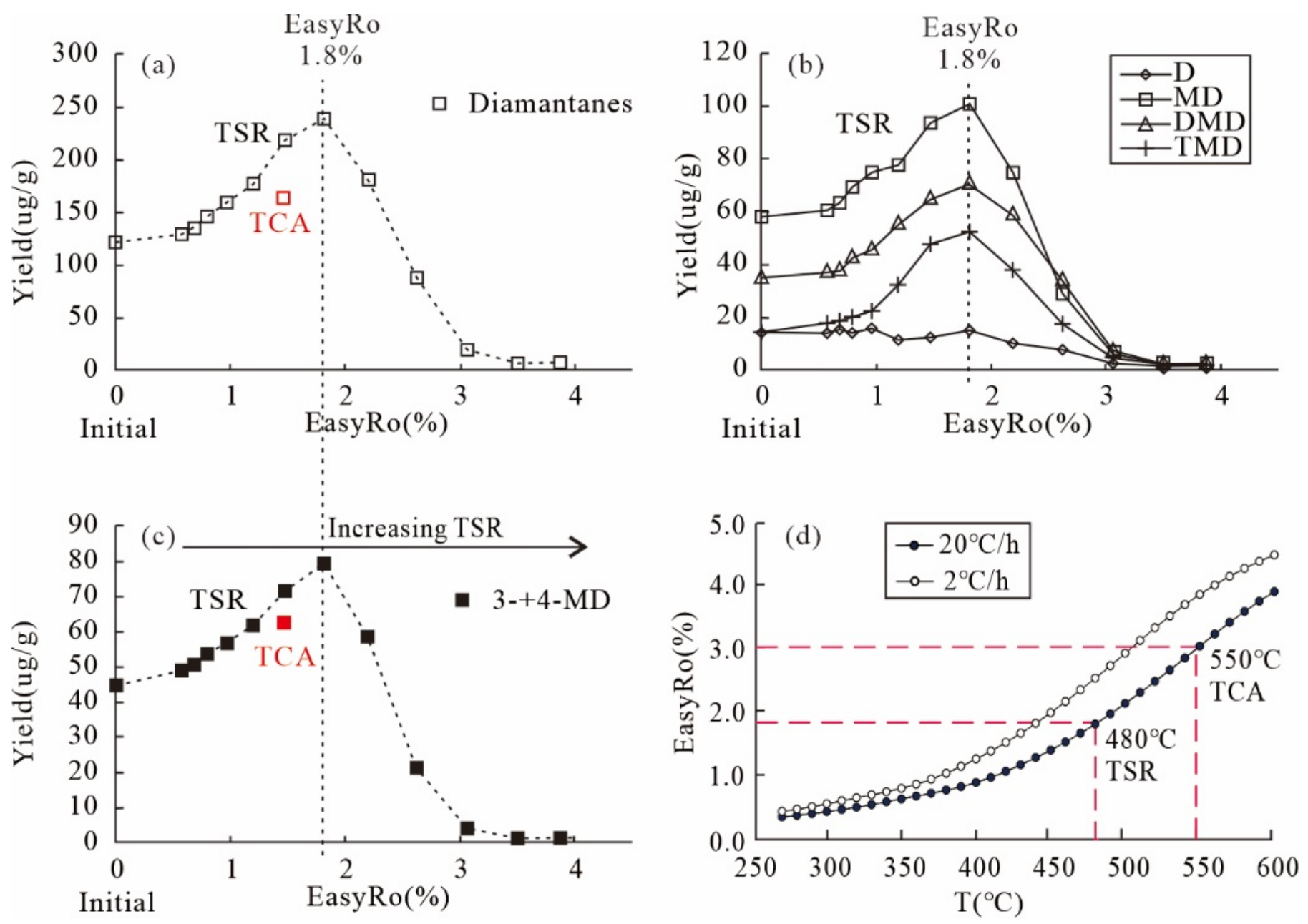

Figure 5

Plots showing the correlation of EasyRo $(\%)$ or heating temperature $\left({ }^{\circ} \mathrm{C}\right)$ with the yields of diamantanes ( $\mu \mathrm{g} / \mathrm{g}$ oil) in the TSR experiments (Group1): (a) diamantanes versus EasyRo, (b) different types of diamantanes versus EasyRo, (c) 3-+4-MD versus EasyRo; (d) heating temperature versus EasyRo. MD = methyldiamantanes; $\mathrm{DMD}=$ dimethyldiamantanes; $\mathrm{TMD}=$ trimethyldiamantanes. 

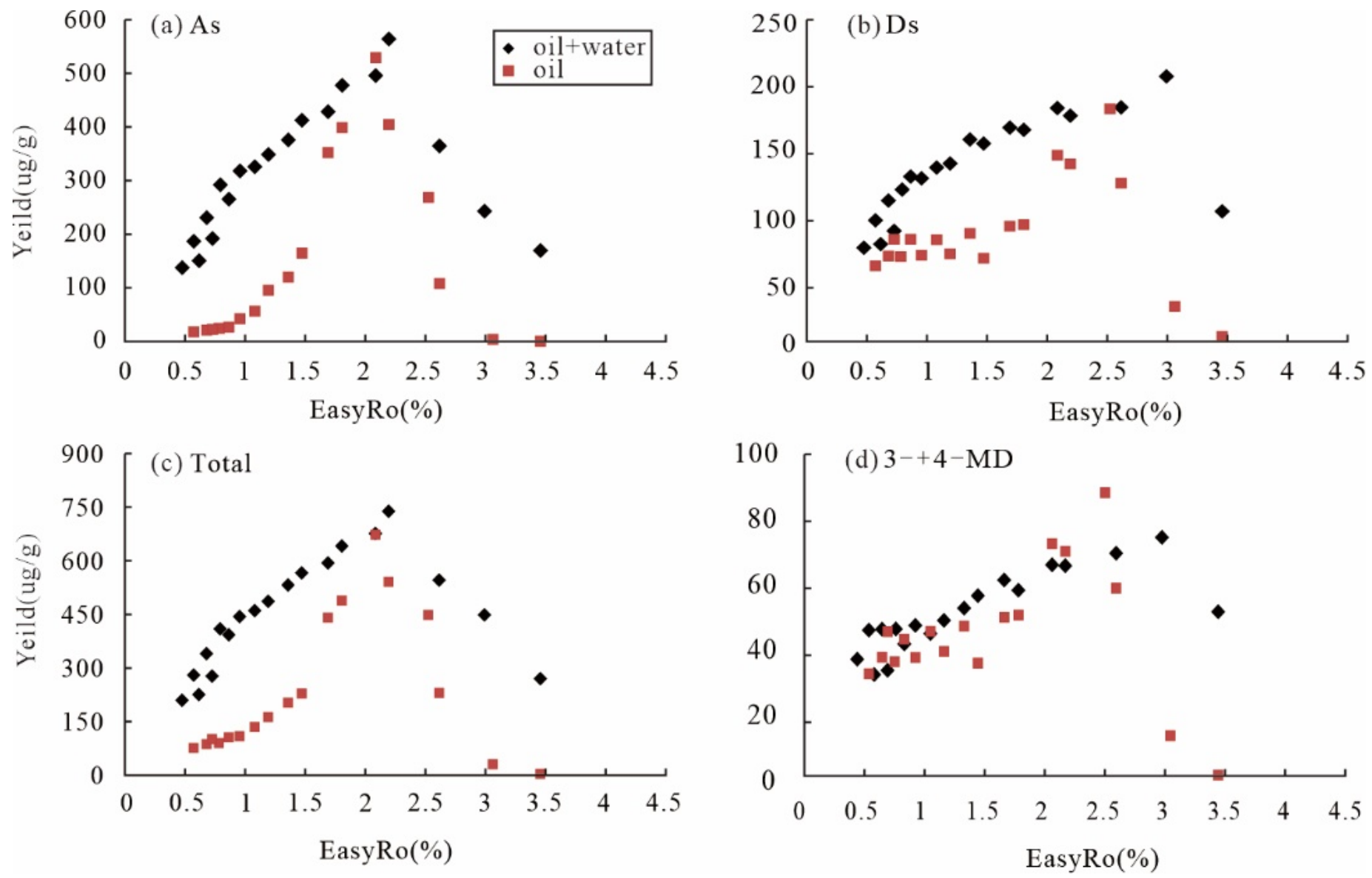

Figure 6

Variation in the yields ( $\mu \mathrm{g} / \mathrm{g}$ oil) of diamondoids generated from hydrothermal and Fang et al. (2012)'s anhydrous pyrolysis of the same oil with EasyRo (\%): (a) As, (b) Ds, (c) Total, (d)3-+4-MD. As = Adamantanes; Ds = Diamantanes. 

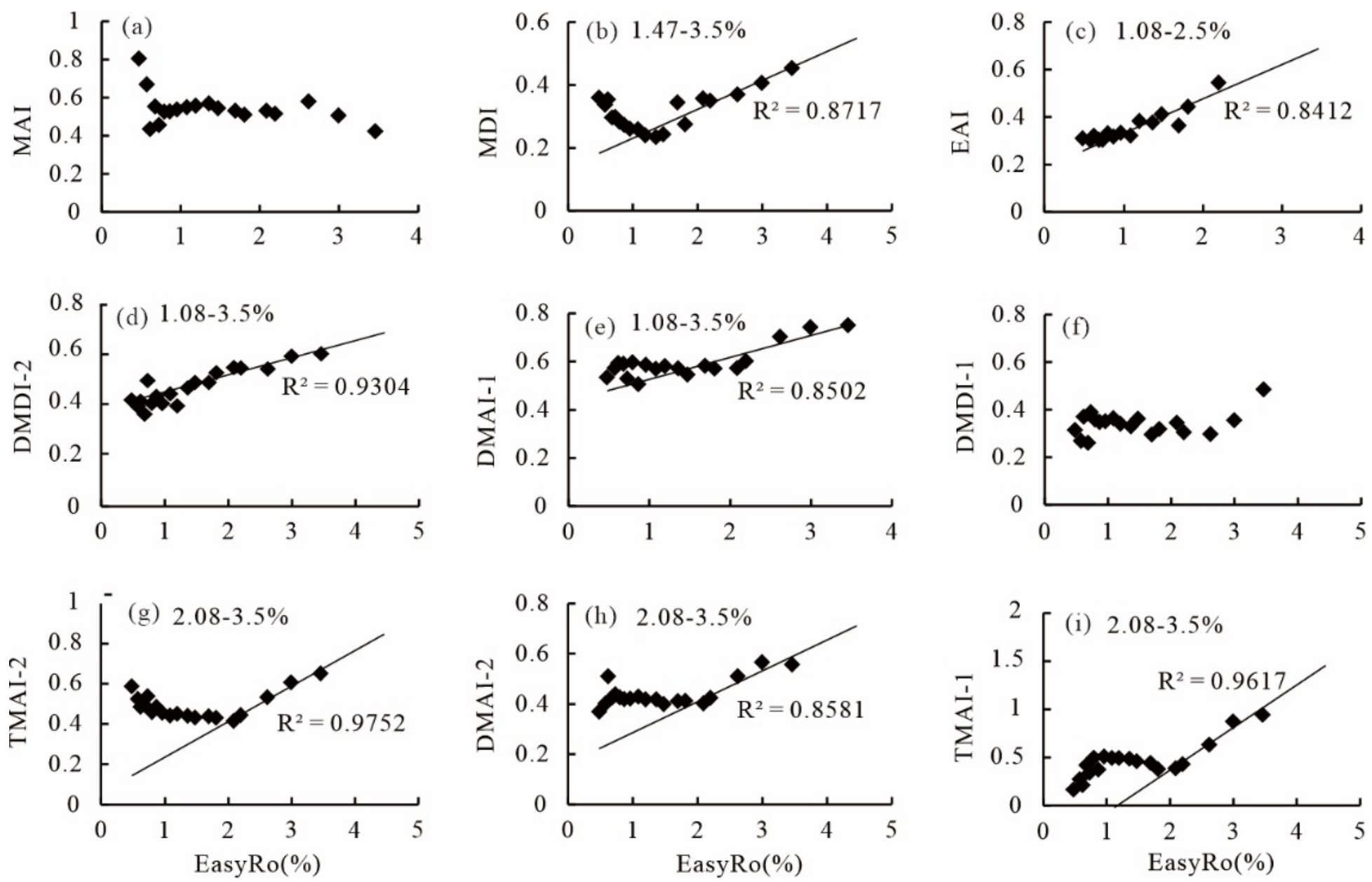

Figure 7

Plots showing the variation of diamondoid indices (MAI, MDI, DMAI-1, DMAI-2, DMDI-1, EAI, TMAl-1 and TMAI-2) with EasyRo (\%) from anhydrous and hydrothermal pyrolysis of oil. MAI = 1-MA/(1-MA + 2-MA), MDI = 4-MD/(4-MD + 1-MD + 3-MD), DMAI-1 = 1,3-DMA/(1,2-DMA + 1,3-DMA), DMAI-2 = 1,3$\mathrm{DMA} /(1,2-\mathrm{DMA}+1,4-\mathrm{DMA}), \mathrm{DMDI}-1=3,4-\mathrm{DMD} /(4,9-\mathrm{DMD}+3,4-\mathrm{DMD}), \mathrm{DMDI}-2$ = 4,8-DMD/(4,9-DMD + 4,8-DMD), EAI = 2-EA/(1-EA + 2-EA), TMAI-1 = 1,3,5TMA/(1,3,5-TMA + 1,3,4-TMA), TMAI-2 = 1,3,5-TMA/(1,3,5-TMA + 1,3,6-TMA).7. 

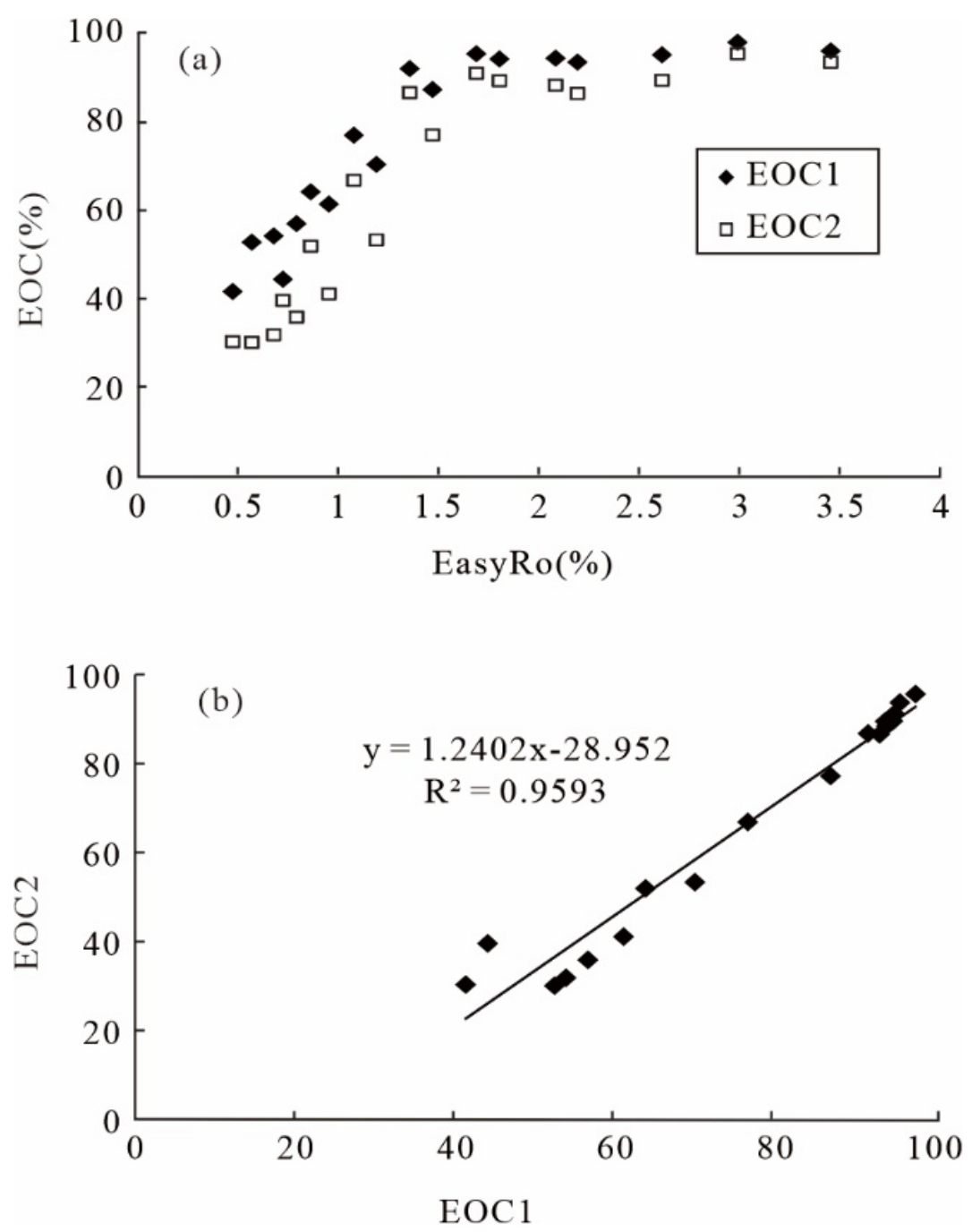

Figure 8

Relationships between: (a) EOC (\%) and EasyRo (\%), (b) the actual EOC2 (\%) and the calculated EOC1 (\%). EOC1: the calculated EOC (\%) from (1- CO/Cc) $\times$ 100; EOC2: the actual EOC (\%). 

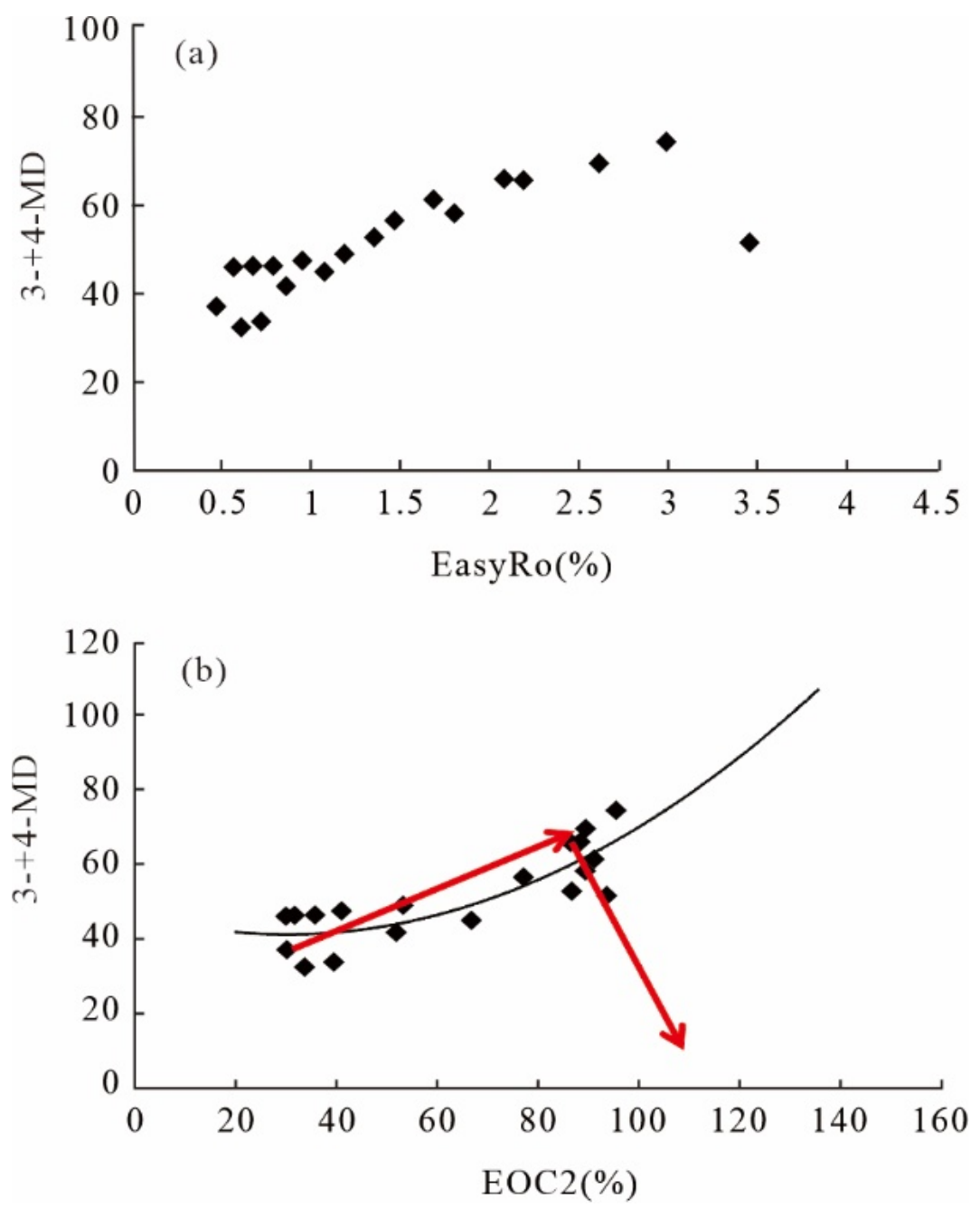

Figure 9

Relationships between: (a) the yield of 3-+4-MD and EasyRo (\%), (b) the yield of 3-+4-MD and EOC (\%). 

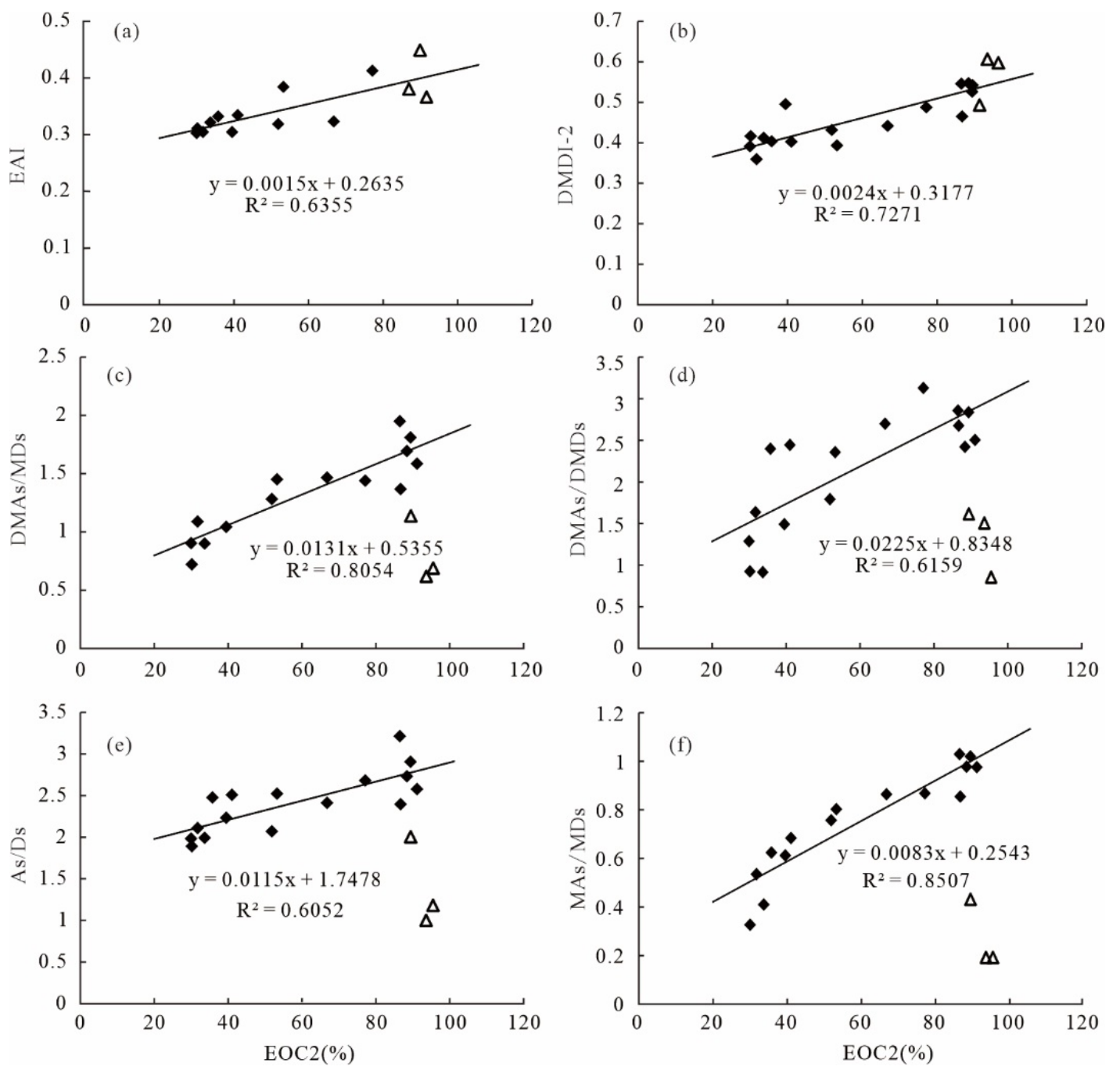

\section{Figure 10}

Relationships between diamondoid-related proxies and EOC2 (\%): (a) EAl; (b) DMDI-2; (c) DMAs/MDs, (d) DMAs/DMDs, (e) As/Ds, (f) MAs/MDs. Triangles indicate data from EasyRo> 3.0\%.

(a)

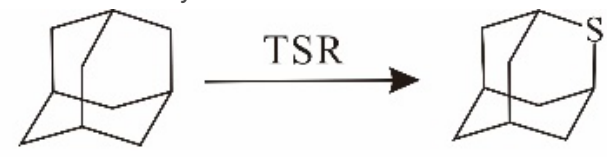

(b)

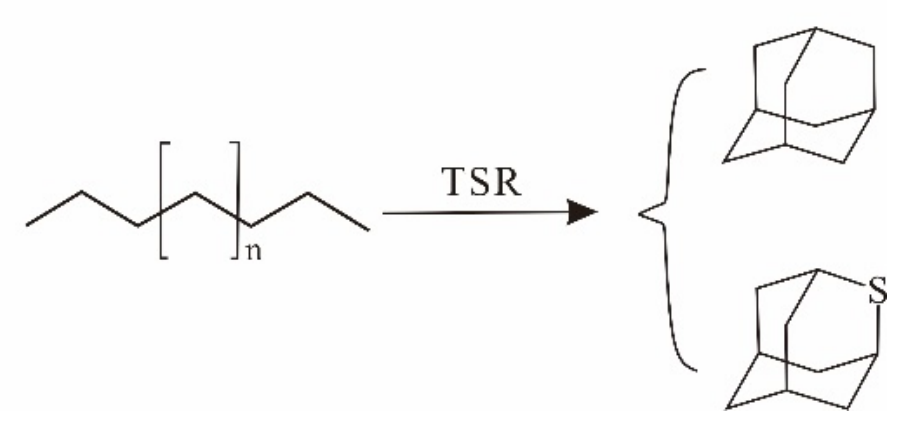

Figure 11

Possible pathways for the formation of diamondoids and thiadiamondoids from the TSR experiments. (a) thiadiamondoids generated from diamondoids (Wei et al., 2007; Gvirtzman et al., 2015); (b) thiadiamondoids generated from non-cage hydrocarbons. 


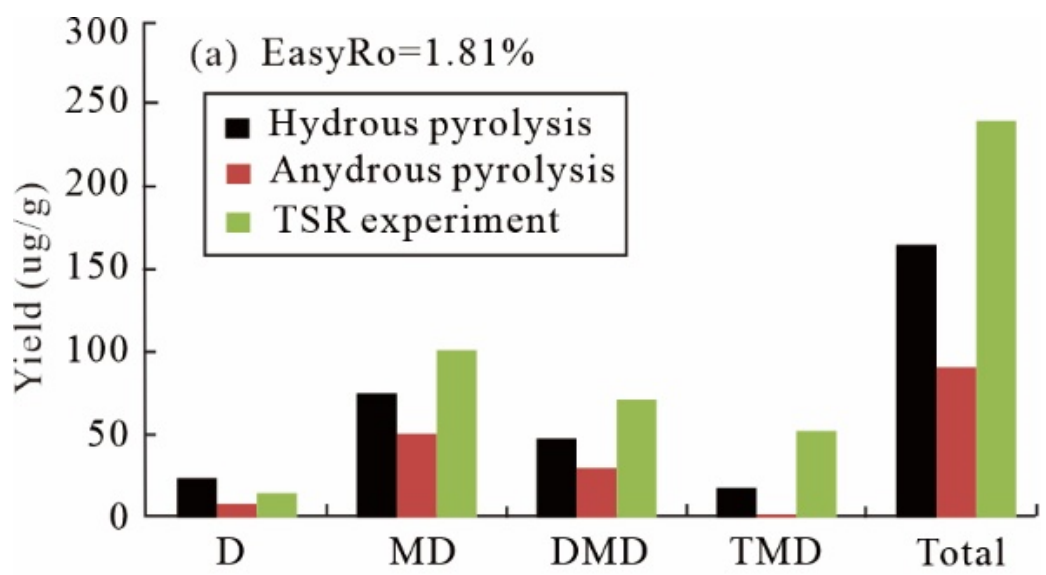

(b) EasyRo=1.81\% TSR experiments

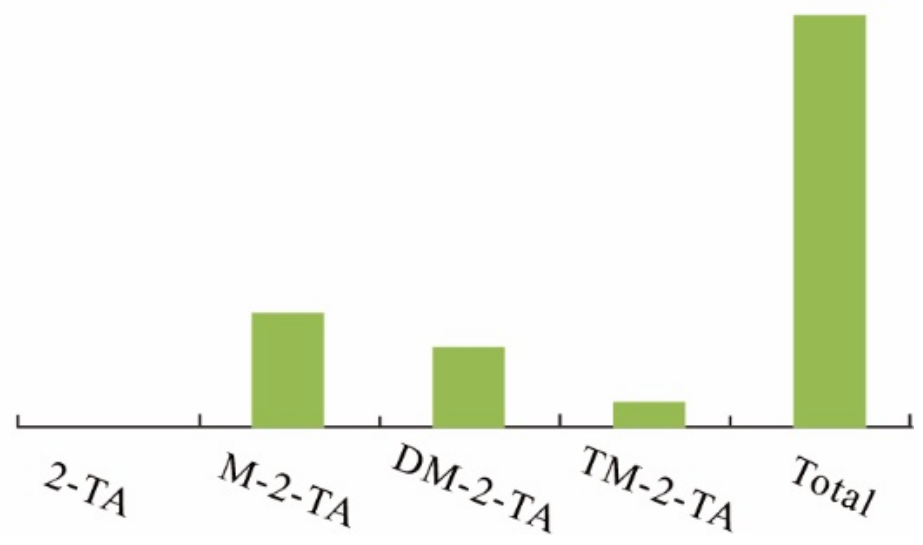

Figure 12

Different types of diamantanes and thiaadmantanes hydrocarbons at $1.81 \%$ EasyRo: (a) variation in the yields ( $\mu \mathrm{g} / \mathrm{g}$ oil) of different types of diamantanes from hydrous pyrolysis, anhydrous pyrolysis, and TSR experiments; (b) the relative concentration of thiaadmantnes from TSR experiments. hydrothermal pyrolysis, anhydrous pyrolysis, and TSR experiments (Group1); (b) the relative concentration of thiaadmantnes from TSR experiments. 2-TA = 2thiaadmantane; M-2-TA = Methyl-2-thiaadmantane; DM-2-TA = Dimethyl-2-thiaadmantane; TM-2-TA= Trimethyl-2-thiaadmantane.Different types of diamantanes and thiaadmantanes hydrocarbons at $1.81 \%$ EasyRo: (a) variation in the yields ( $\mu \mathrm{g} / \mathrm{g}$ oil) of different types of diamantanes from hydrous pyrolysis, anhydrous pyrolysis, and TSR experiments; (b) the relative concentration of thiaadmantnes from TSR experiments.

\section{Supplementary Files}

This is a list of supplementary files associated with this preprint. Click to download.

- supplementaryTableS1.docx 